Emerging Adults' Views about Couple and Personal Satisfaction in Various Gender Role Relationships

\begin{tabular}{l} 
A Dissertation Presented to \\
The Faculty of the Graduate School \\
At the University of Missouri \\
\hline In Partial Fulfillment \\
Of the Requirements for the Degree \\
Doctor of Philosophy \\
BA \\
TAMARA G. COON SELLS \\
Dr. Lawrence Ganong, Dissertation Supervisor \\
DECEMBER 2012
\end{tabular}


(C) Copyright by Tamara G. Coon Sells 2012

All Rights Reserved 
The undersigned, appointed by the dean of the Graduate School, have examined the dissertation entitled

\section{EMERGING ADULTS' VIEWS ABOUT COUPLE AND PERSONAL SATISFACTION IN VARIOUS GENDER ROLE RELATIONSHIPS}

presented by Tamara G. Coon Sells, a candidate for the degree of Doctor of Philosophy, and hereby certify that, in their opinion, it is worthy of acceptance.

Professor Lawrence Ganong

Professor Jean Ispa

Professor Duane Rudy

Professor Peggy Placier

Professor Colleen Colaner 
I dedicate this paper to my parents, my husband, and my daughter, who were patient and provided me with everlasting support throughout this process. 


\section{ACKNOWLEDGEMENTS}

I would like to thank the faculty and graduate students of the Department of Human Development and Family Studies at the University of Missouri for providing me with the knowledge and skills required to complete this process. Dr. Mark Fine, thank you for your support in the initial stages of this process and for mentoring me throughout most of my graduate career. Dr. Larry Ganong, thank you for mentoring me throughout this study and for helping me become a better researcher and writer. I would also like to thank Drs. Jean Ispa, Duane Rudy, Peggy Placier, and Colleen Colaner for serving as members of my dissertation committee and for making this a positive experience. I am grateful for your feedback and guidance. I would also like to thank my respondents for sharing their opinions and offering detailed explanations of their perceptions. Without your participation, this study would not have been possible. 


\section{TABLE OF CONTENTS}

ACKNOWLEDGEMENTS …………………….......................................... ii

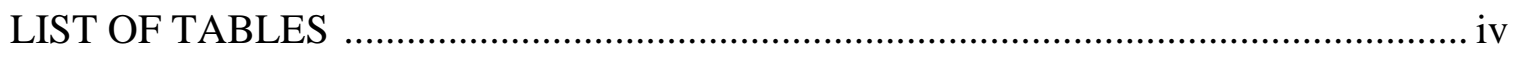

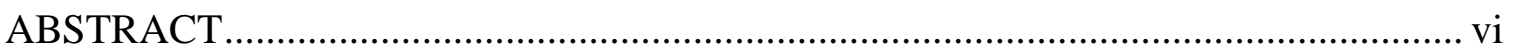

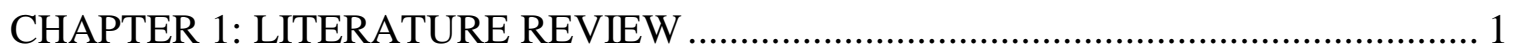

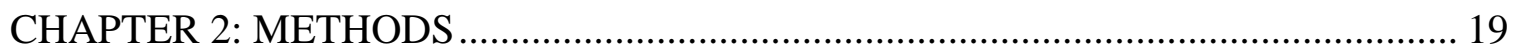

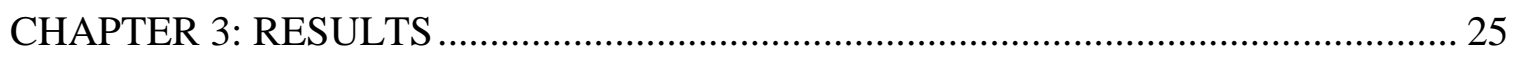

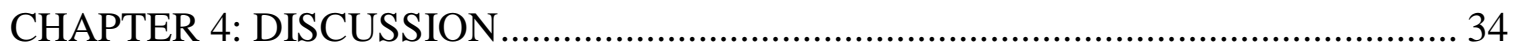

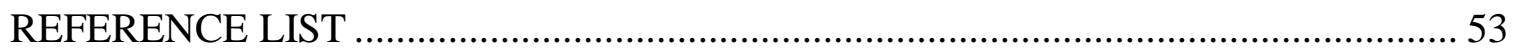

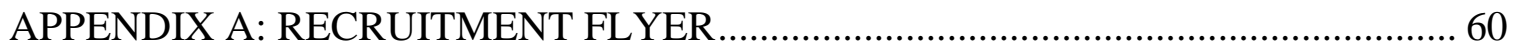

APPENDIX B: INFORMED CONSENT/COVERLETTER ………………………........ 63

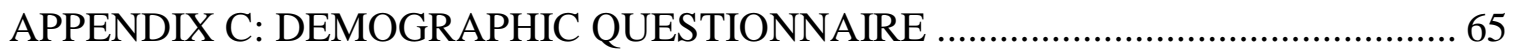

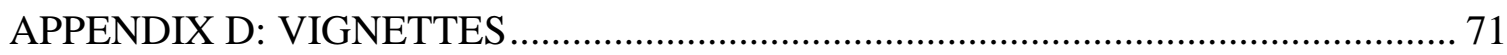

APPENDIX E: PERCEIVED RELATIONSHIP SATISFACTION MEASURE ............. 76

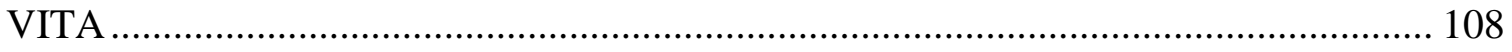




\section{LIST OF TABLES}

Table 1 Frequency Distributions among Demographic Variables.................................. 80

Table 2 Descriptive Statistics and Intercorrelations among Study Variables ................. 82

Table 3 Means and Standard Deviations of CSSD and APS by GRR, Marital Status,

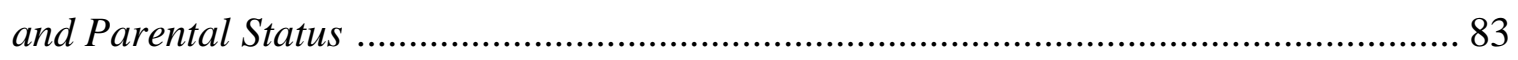

Table 4 Multivariate tests for the effects of GRR, Marital Status, and Parental Status on

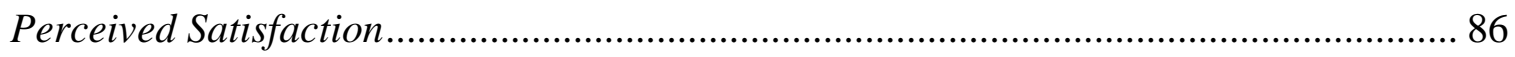

Table 5 Univariate tests for the effect of GRR on Perceived Satisfaction ........................ 87

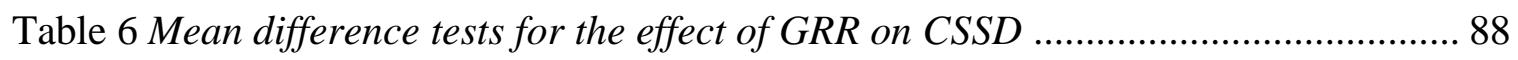

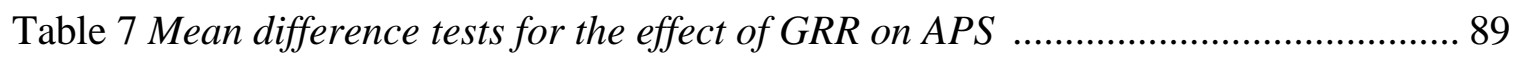

Table 8 Male-Head/Female-Complement GRR Regression Analyses ............................ 90

Table 9 Male-Senior/Female-Junior GRR Regression Analyses ................................. 91

Table 10 Partner-Equal GRR Regression Analyses .................................................... 92

Table 11 Female-Senior/Male-Junior GRR Regression Analyses ................................. 93

Table 12 Female-Head/Male-Complement GRR Regression Analyses ........................... 94

Table 13 Qualitative Codes and Examples Derived from Respondents' CSSD and APS

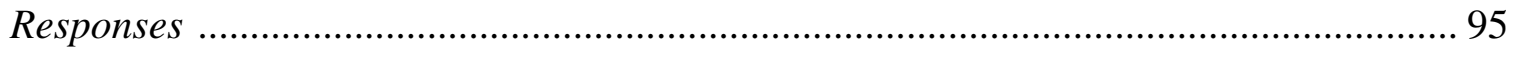

Table 14 Rationale for Respondents' CSSD Responses based on GRR Assignment ....... 96

Table 15 Rationale for Respondents ' APS Responses based on GRR Assignment .......... 98

Table 16 Rationale for Respondents' CSSD Responses based on Marital Status

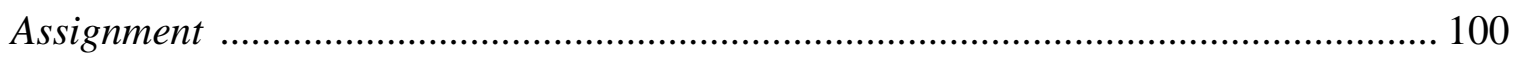

Table 17 Rationale for Respondents’ APS Responses based on Marital Status

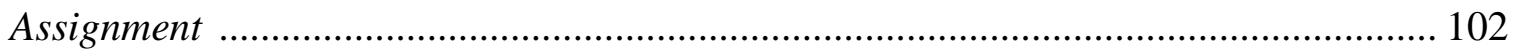


Table 18 Rationale for Respondents' CSSD Responses based on Parental Status

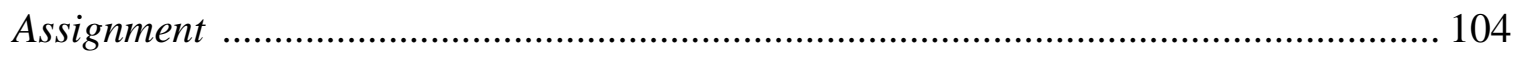

Table 19 Rationale for Respondents' APS Responses based on Parental Status

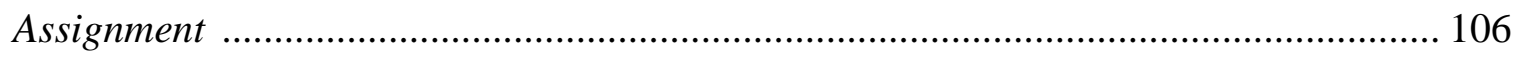




\begin{abstract}
Using vignettes as a data collection tool, the main purpose of this randomized, mixedmethod study was to examine emerging adults' views about satisfaction of couples in various types of gender role relationships and their anticipated satisfaction if they were in such gender role relationships: (1) male-head/female-complement, (2) malesenior/female-junior partner, (3) partner-equal, (4) female-senior/male-junior partner, and (5) female-head/male-complement. Secondary purposes of the study were to examine the relation of selected personal characteristics to views about satisfaction, and whether or not marital and parental status of couples in various gender role relationships were related to views about relationship satisfaction. Quantitative analyses revealed that emerging adults perceived egalitarian gender role relationships to be the most satisfying type of relationship. Further, views about the satisfaction of couples and anticipated personal satisfaction in various gender role relationships were not dependent on the marital or parental status of couples. Qualitative results were generally supportive of the quantitative findings, in that egalitarian gender role relationships were perceived to be the most satisfying. The majority of respondents related the vignette couple to their personal desires and life experiences.
\end{abstract}




\section{CHAPTER 1: LITERATURE REVIEW}

The purpose of this study is to examine emerging adults' views about couple and personal satisfaction in various types of gender role relationships (GRR). Emerging adulthood is considered to be a transitional period between adolescence and adulthood characterized by independent exploration, and usually consisting of individuals between the ages of 18 and 29 (Arnett, 2004). In this study, gender roles in heterosexual relationships are thought of as the degree to which each partner in the relationship adopts and practices various behaviors often associated with gendered roles of men and women. Although historically and cross-culturally inaccurate, in the United States these stereotypical gendered roles for men and women in families have been referred to for decades as "traditional." This label is used in this dissertation to link the study with prior studies in which this label has been used.

Gender role relationships fall on a continuum, marked by varied gendered practices of traditionalism in the workforce and within the family (i.e., household and childrearing responsibilities, and family decision-making). For the purposes of this study, at one end of this GRR continuum are traditional, or conventional, couples who enact stereotypical gendered roles, with male partners as breadwinners and chief household decision makers and female partners as subservient to the men, focusing their energies on raising children, maintaining households, and providing emotional support to family members (Scanzoni, Polonko, Teachman \& Thompson, 1989). On the other extreme of the GRR continuum are nontraditional, or nonconventional, couples who reverse these gendered roles in their daily interactions, with female partners in charge of work and family decisions, and male partners taking supportive roles. The middle of this range of GRRs is characterized as egalitarian, with less gender-stereotyped behaviors and relatively equal and mutual sharing of work and family responsibilities by both male and female partners.

For decades following World War II, normative adult gender roles in U.S. families were traditional, with men typically serving as the sole or primary breadwinner and women primarily 
responsible for childrearing and domestic duties (Coontz, 1998). Over the past several decades there has been a trend among women to depart from these stereotypical feminine gender roles in families by attaining higher educations and engaging in work outside of the home, sometimes in time-demanding careers. In fact, the percentage of women in the workforce has increased significantly over the past several decades, reaching nearly $60 \%$ in 2011, and is expected to continue to rise (U.S. Census Bureau, Current Population Survey, Labor Force Statistics, 2011). Not surprisingly, gender roles in marriages and other intimate romantic relationships also have been changing, from a preponderance of male-headed to more egalitarian unions (Boushey, 2009; Cabrera, Tamis-LeMonda, Bradley, Hofferth, \& Lamb, 2000; Pleck, 2010).

Along with the enactment of egalitarian gender roles, there has been an increase in the numbers of individuals who subscribe to egalitarian gender role attitudes and beliefs (Bolzendahl \& Myers, 2004; Brewster \& Padavic, 2000; Cichy, Lefkowitz, \& Fingerman, 2007; Thornton \& Young-DeMarco, 2001; Zuo \& Tang, 2000). This general movement away from traditional gendered role ideologies in intimate romantic relationships (i.e., marriage and/or cohabitating relationships) may introduce tension and problems in relationships (Amato \& Booth, 1995; Rogers \& Amato, 1997), possibly because of increased ambiguity in marital gender role expectations and performances (Scanzoni et al., 1989). Although researchers have explored the status of gender role ideologies over time, views about which gender role relationships are perceived to be the most satisfying has not been explored. Even less is known about how marital status (i.e., married versus unmarried, cohabiting) and parental status (i.e., child-present versus child-absent) interact with different gender role relationships to predict views about relationship satisfaction. These are gaps in the literature worth exploring, particularly among emerging adults, because understanding which gender role divisions in couple relationships are perceived to be the most satisfying 
may advance our knowledge of the stereotypes this group of adults hold of gender role relationships, as well as help predict which gender role divisions they will choose for themselves in the future.

Below is a review of the different types of gender role relationships examined in the current study, followed by a review of literature focused on emerging adults' gender role attitudes and their expectations for future long-term romantic partnerships. Finally, literature that has examined emerging adults' expectations of relationship satisfaction across the varying types of gender role relationships is discussed.

\section{Types of Gender Role Relationships}

The present study builds on two prior investigations of gender role relationships. In the first study, Scanzoni and colleagues (1989) identified three categories of gender role relationships in marriages: (1) head-complement, (2) junior-senior partnership, and (3) equal-partnership. In their typology, two categories described traditional gendered practices across the spheres of work and family, with husbands as family heads or family leaders, and wives in supportive roles (although they are in charge of child caregiving), while the third described egalitarian practices. Cobb, Seery, and McKinney (2003) later added a fourth category, wife-as-senior partner/husband as junior partner, which characterizes a nontraditional GRR in which the female is the primary breadwinner but both partners earn wages and participate in childrearing. Following the basic premises of Scanzoni et al. (1989) and Cobb et al. (2003), I adapted these typologies for the current study in three ways: (a) by relabeling them to more clearly describe the variations in GRR divisions, (b) by proposing a fifth type of GRR that acknowledges the possibility of a female-head/male-complement dyad, and (c) by examining attitudes about the perceived satisfaction in these relationships by adding marital and parental status as variables. Below is a detailed description of each of the five GRR types.

Male-head/female-complement. Scanzoni et al. (1989) originally labeled this type of marital relationship dyad as the husband-complement arrangement. This type of relationship is characteristic of 
the conventional, or traditional, relationship in that work and family roles are segregated by males and females in a gender-stereotyped way. That is, the adult male is the sole economic provider for the family, while the adult female assumes all of the household and childrearing responsibilities (e.g., parenting, homemaking, emotional supporting, and other kinds of domestic caring). It is also traditional in the sense that the male is the sole, or at least primary, decision-maker in the family regarding how finances are allocated because the female does not have financial resources beyond what is given to her by her partner (Scanzoni \& Scanzoni, 1988).

Male-senior/female-junior. This type of relationship dyad was originally referred to as the juniorsenior partner arrangement by Scanzoni et al. (1989) and is slightly less traditional than the malehead/female-complement GRR. Although it is characterized by both partners economically providing for the family, males' labor force participation is viewed as "senior" and more significant than females'. Still characteristic of a gender-traditional relationship, women in this type of relationship assume the majority of the household and childrearing responsibilities; however, males contribute a small amount to these tasks as well. Also, because females in this type of partnership have additional resources beyond what is presented to them by their partners, they hold more financial decision-making power than females of the male-head/female-complement relationship type (Scanzoni \& Scanzoni, 1988). They do not hold as much decision-making power as their partners, however.

Partner-equal. Scanzoni et al. (1989) originally referred to this type of relationship dyad as the equal partner arrangement. The partner-equal gender role relationship is an egalitarian relationship in that gender roles are interchangeable and great significance is placed on equity and fairness among partners. Both partners in this relationship contribute equally to the paid labor force and are equally responsible for meeting family responsibilities. Additionally, males and females consider both of their occupations as 
equally important, and share power and negotiate family financial decisions on a more equal playing field than partners in the previously described GRRs (Scanzoni \& Scanzoni, 1988).

Female-senior/male-junior. Cobb et al. (2003) added this relationship dyad to the three-groups created by Scanzoni et al (1989). This type was labeled the wife-as-senior partner dyad and is best understood as the gender-reversal of the male-senior/female-junior gender role relationship (Cobb et al., 2003). This dyad is a nonconventional, or nontraditional, partner form and is characterized by both partners economically providing for the family. The female's labor force participation, however, is viewed as "senior" and as more significant than the male's. Additionally, men in this type of relationship assume the majority of the household and childrearing responsibilities, while women contribute a smaller amount to these tasks. Also, because females in this type of partnership are the primary breadwinners, they hold the majority of the decision-making power regarding how finances are allocated, although males have some power as well (Scanzoni \& Scanzoni, 1988).

Female-head/male-complement. This type of GRR is added to the four identified by Cobb et al (2003). It is best understood as the gender-reversal of the male-head/female-complement partnership. Like the male-head/female-complement partnership, this dyad is characterized by segregated work and family roles. However, in this dyad, the female is the sole economic provider for the family, while the male assumes all of the family responsibilities (e.g., parenting, homemaking, emotional supporting, and other kinds of domestic caring). It is nonconventional, or nontraditional, also in the sense that the female is the sole, or at least primary, financial decision-maker in the family because the male does not have resources available to him beyond what is presented to him by his partner.

The female-head/male-complement type of GRR is important to acknowledge because this arrangement is becoming more popular amongst couples today. Up from 140,000 in 2008, there were an estimated 176,000 married fathers in 2011 who stayed at home to care for their family while their wives 
worked full-time in the labor force in (U.S. Census Bureau, Current Population Survey, 2008 Annual Social and Economic Supplement, Table FG8, 2008; U.S. Census Bureau, Current Population Survey, 2011 Annual Social and Economic Supplement, Table FG8, 2011). These statistics may underestimate the actual number of couples who practice this gender role division, however, because they only include those couples with children under the age of 15 . It is expected that there are married couples without children, as well as unmarried, cohabitating couples who also engage in female head/male complement gender roles.

Summary. In general, gender role relationships in romantic relationships may be categorized as: (1) male-head/female-complement, (2) male-senior/female-junior, (3) partner-equal, (4) femalesenior/male-junior, and (5) female-head/male-complement. These five types of GRRs vary in the work and family roles in which males and females engage and are understood by the level of "traditionalism" in gender roles. For instance, male-head/female-complement and male-senior/female-junior partnerships are generally understood as traditional gender role divisions because the male is the primary breadwinner and the female is the primary family caregiver, whereas the partner-equal partnership is generally understood as an egalitarian gender role division because the male and female equally share the roles of worker and family caregiver (Scanzoni et al., 1989). Finally, female-senior/male-junior and female-head/malecomplement partnerships are generally understood as nontraditional gender role divisions because the female is the primary breadwinner and the male is the primary family caregiver (Cobb et al., 2003).

\section{Attitudes toward, and Expectations of, Gender Roles in Romantic Relationships}

Gender role attitudes in marriages and other unions have changed dramatically over the last several decades. It is well-documented that Americans' attitudes toward marital gender roles (i.e., men's and women's work and family roles) have become increasingly more egalitarian since the 1950's (Bolzendahl \& Myers, 2004; Brewster \& Padavic, 2000; Cichy et al., 2007; Thornton \& Young-DeMarco, 2001; Zuo \& Tang, 2000). However, not everyone holds egalitarian beliefs about marriage. Individuals differ in their 
attitudes about marital gender roles based on their gender, level of education, religiosity, level of income, and certain familial characteristics. Many of these demographic variables also tend to be related to gender role expectations.

Gender. Although female and male college students have similar levels of commitment to future occupational (Blakemore, Lawton, \& Vartanian, 2005; Friedman \& Weissbrod, 2005), and future marital, parental, and domestic roles (Freidman \& Weissbrod, 2005), women's attitudes toward marital gender roles are more egalitarian than are men's (Bolzendahl \& Myers, 2004; Brewster \& Padavic, 2000 Bryant, 2003; Cichy et al., 2007; Mickelson, Claffey, \& Williams, 2006; Pearce \& Thornton, 2007; Powers et al., 2003; Thornton \& Young-DeMarco, 2001; Zuo \& Tang, 2000). Botkin, Weeks, and Morris (2000) have also documented an increasing trend over the past few decades for female college students to expect the practice of egalitarian gender roles in their future marriages. Further, women expect to combine career and family roles concurrently rather than consecutively (Davey, 1998; Morgan \& Affleck, 1989) and to give priority to both career and family roles (Hoffnung, 2004; Kerpelman \& Schvaneveldt, 1999; Livingston, Burley, \& Springer, 1996; Schroeder, Blood, \& Maluso, 1993). In fact, 94\% of college women in Morgan and Affleck's (1989) study expected to work full-time at age 25 and the majority of these women expected to combine work and family in their adult lives. In another study, $80 \%$ of the female college students planned to be more committed to their careers than to marriage (Novack \& Novack,1996), and females enrolled in a combined BS/MD program in Hartung and Rogers' (2000) study were equally invested in, and motivated for, both work roles and family roles. These studies indicate that many females may prefer an egalitarian GRR in their future.

However, other researchers report that women have a stronger commitment than do men to family roles (Spade \& Reese, 1991; Greene \& Wheatley, 1992; Niles \& Goodnough, 1996) and to parental roles (Blakemore et al., 2005), suggesting that there is still some support for traditional gendered roles in couple 
relationships. In fact, college men expect to work more hours in paid employment than their female counterparts and college women expect to work more hours in housework than male students (Kaufman, 2005). Moreover, college women expect to have periods of career disruptions as they raise children (Machung, 1989; Schroeder et al., 1992). If women have a stronger commitment to domestic roles, they may expect to have a traditional, rather than an egalitarian, future gender role relationship. This is because men who self-identify as having a traditional gender role ideology tend to expect to put in more hours dedicated to paid work and fewer hours dedicated to housework than men who identify as egalitarian, and women who self-identify as traditional tend to expect to put in more housework hours than egalitarian women (Kaufman, 2005).

In addition to the traditional childcare and domestic expectations observed among emerging adults, traditional expectations concerning relative earnings of husbands and wives may also exist. Novack and Novack (1996) found that more male than female college students would be uncomfortable with a spouse earning more money. Further, Ganong and Coleman (1992) found that college men and women differed in what they expected from their future partners. Women expected that their future husbands would be more successful, make more money, have a higher education, be more intelligent, and be better able to handle things than men expected of their future wives. This expectation of traditional gender roles was supported by later research by Ganong, Coleman, Thompson, and Goodwin-Watkins (1996). Using a sample of both African American and European American college students, Ganong et al. (1996) found that women of both races expected their future husbands to be more intelligent, better able to solve problems, more professionally successful, and make more money than themselves. Men of both races also expected that their future partners would spend more time in parenting roles than themselves.

In sum, researchers have found conflicting evidence about the emergence of a preference for egalitarian gender roles among college men and women. Generally, men and women alike expect to 
engage in and be committed to educational, occupational, and marital roles, but a gender difference appears on the expected engagement in and commitment to childcare and domestic roles. Keeping with a traditional view on childcare and domestic labor, females are still expected to spend more time caring for children and in housework than their spouses.

Education. Education level is significantly related to attitudes toward gender roles in marriage; those with more education are more likely than those with less education to hold egalitarian marital gender role beliefs (Bolzendahl \& Myers, 2004; Brewster \& Padavic, 2000; Bryant, 2003; Cunningham, Beutel, Barber, \& Thornton, 2005; Fan \& Marini, 2000; Kulik, 2002; Marks, Lam, \& McHale, 2009; Tallichet \& Willits, 1986). It is thought that more educational experiences increase individuals' exposure to egalitarian ideas and to challenges to traditional myths and stereotypes about gender (Cassidy \& Warren, 1996; Davis \& Robinson, 1991; Rhodebeck, 1996). No studies to date have examined the role of education on emerging adults' anticipated satisfaction in their future gender role relationships.

Religiosity. Because many religions promote and reinforce traditional gender beliefs, increased religious practice and service attendance (Pearce \& Thornton, 2007; Peek, Lowe, \& Williams, 1991), as well as a strong religious affiliation (Leech, 2010; Pearce \& Thornton, 2007) are negatively related to marital gender role egalitarianism. Having no religious affiliation, or low levels of religiosity, is negatively related to having a traditional gender role ideology (Pearce \& Thornton, 2007).

Bang, Hall, Anderson, and Willingham (2005) examined the role of religiosity on emerging adults' expectations for their future GRRs and found that women who hold strong orthodox fundamental beliefs (i.e., literal interpretation of Scripture, sinfulness of humans, and fear of eternal punishment from God) are also less likely than women who hold weaker fundamental beliefs to expect to engage in future egalitarian marriage roles. Generally, religious affiliation predicts emerging adults' gender role expectations for their 
future long-term romantic partnerships. Those who hold strong orthodox beliefs are more likely to expect a traditional marriage than those who hold less orthodox beliefs.

Income. Marks et al. (2009) found that men and women who have higher income levels express more egalitarian GRR beliefs, while individuals who have lower income levels hold more traditional gender role beliefs. This finding may be explained by the fact that income and education levels are highly correlated. Therefore, individuals who have been exposed to egalitarian ideas through education carry these views with them when they enter the work force. No studies to date have examined the role of income on emerging adults' expectations for their future GRRs. Because the current study is interested in learning about how emerging adults view satisfaction in GRRs and this sample includes college students who typically do not have an income separate from their parents, the income level of respondents' family of origin is examined as a possible factor that is associated with their views on gender roles.

Familial characteristics. Increased maternal employment (Bolzendahl \& Myers, 2004; Fan \& Marini, 2000; Kulik, 2002), increased maternal education levels (Bolzendahl \& Myers, 2004; Fan \& Marini, 2000; Kulik, 2002; Pearce \& Thornton, 2007), and increased paternal education levels (Pearce \& Thornton, 2007) are associated with increased egalitarian attitudes regarding marital gender roles in children. Additionally, just as socialization theories posit, parents' gender role ideologies have been shown to be positively related to children's attitudes toward gender roles in marriage (Cunningham, 2001; Davis \& Wills, 2011; Marks et al., 2009). For example, individuals who have an egalitarian mother or father are more likely themselves to hold egalitarian beliefs for gender roles in marriage (Davis \& Wills, 2011; Marks et al., 2009; Myers \& Booth, 2002; Thornton, Alwin, \& Camburn, 1983). However, there is also evidence that children tend to hold more egalitarian views for marital gender roles than their parents (Cichy et al., 2007). 
Only one study to date has examined familial characteristics as a possible predictor of emerging adults' gender role expectations in their future romantic partnerships. In an earlier study of high school and college students, Coleman and Ganong (1984) found that family structure of origin (i.e., intact, step, single-parent) did not significantly predict future marriage role expectations in the areas of decisionmaking, wage-earning, housekeeping, and childcare.

Summary of the literature. Although researchers generally report an increase in the numbers of people holding egalitarian gender role ideologies regarding men's and women's work roles and family provider roles, certain groups of people are more likely to adopt such views than are others. Females, as well as those who have increased education and income, hold liberal religious views, have mothers who work outside of the home, have parents with an increased education level, and have parents who hold egalitarian gender role ideologies are more likely to hold egalitarian marital gender role ideologies. Gender and religiosity have also been shown to predict emerging adults' gender role expectations for their future marriages. Men and women expect to combine and excel in both work and family roles. Women, however, are still expected to spend more time in caregiving roles than men. Also, greater religiosity has been shown to be negatively related to egalitarian gender role expectations for future romantic partnerships, whereas family structure has not been shown to predict expectations in either direction.

\section{Emerging Adults' Expectations of Marital Satisfaction across Types of Gender Role Relationships}

Researchers may have assumed in the past that emerging adults' gender role expectations for their future marriages reflect not only what they expect to experience, but what they view as the most personally satisfying and most fulfilling gender role divisions in their future marriages. This may not be the case, however, because gender role expectations may reflect social norms rather than what is deemed as personally satisfying. Further, although researchers have studied married couples' satisfaction with their gender roles (Dillaway \& Broman, 2001; Helms, Walls, Crouter, \& McHale, 2010; Helms-Erikson, 
Tanner, Crouter, \& McHale, 2000; Perry-Jenkins \& Folk, 1994; Wilkie, Ferree, \& Ratcliff, 1998), it cannot be assumed that these findings are generalizable to emerging adults' views about the level of relationship satisfaction across different types of gender role relationships. Men and women do not always find themselves in the type of gender role arrangement that they deem as the most fulfilling.

It also should not be assumed that prior studies were implicitly measuring views about satisfaction in GRRs. Results from Cobb et al.'s (2003) study suggest that emerging adults perceive egalitarian GRRs as the most satisfying. When presented with four different marital dyads depicting either a husbandhead/wife-complement (i.e., the husband is the sole breadwinner and wife is the sole homemaker and childcare provider), husband-senior/wife-junior (i.e., the husband is the primary breadwinner and assumes a small amount of housework and childcare responsibilities, while the wife provides a supplemental income and assumes the majority of the housework and childcare responsibilities), spouse-equal (i.e., the husband and wife both hold prestigious careers and equally share housework and childrearing responsibilities), or wife-senior/husband-junior (i.e., the wife is the primary breadwinner and assumes a small amount of housework and childcare responsibilities, while the husband provides a supplemental income and assumes the majority of the housework and childcare responsibilities) marriage, emerging adults in Cobb et al.'s (2003) study perceived that both husbands and wives would be significantly more satisfied in the spouse-equal dyad than any other dyad type. However, husbands were perceived to be significantly more satisfied than wives in the two conventional dyads (i.e., husband-head/wifecomplement and husband-senior/wife-junior partner). These results suggest that although emerging adults view egalitarian marriages as the most satisfying for both husbands and wives, husbands are thought to be more satisfied in traditional marriages than are wives, and wives are thought to be more satisfied in nontraditional marriages than are husbands. 
Emerging adults' views about satisfaction with different types of GRRs are products of changing social norms, values, and practices, so it is important to examine how views may have changed over time. Following similar methods as Cobb et al. (2003), a purpose of the current study is to examine emerging adults' views about the satisfaction of couples in different types of GRRs. This research may advance our understanding of the stereotypes emerging adults hold of gender role relationships. Exploration of emerging adults' perceptions of these relationships will help predict which gender role divisions they may find fulfilling in their future relationships, as well as which type of relationships they may choose for themselves. Educators, as well as pre-marital and marriage counselors, may be able to use this information to help emerging adults prepare for their future GRRs. Also, work/family policy-makers may be able to use this information to better tailor policies to the new trends in gender role relationships.

\section{Gender Role Relationships and Cohabiting Relationships}

No studies have been found in which emerging adults' attitudes and beliefs about gender role relationships in cohabiting relationships have been examined. Couple typologies of GRRs have not been applied to cohabiting relationships. This is a significant gap in the literature, because a majority of young adults are likely to cohabit at some point in their adult lives (U.S. Census Bureau, Current Population Survey, 2011 Annual Social and Economic Supplement, Table UC1, 2011; U.S. Department of Health and Human Services, 2010). Therefore, in this study I also examine emerging adults' views about coupel and personal satisfaction in gender role couple types that are either cohabiting or married. Do emerging adults have similar views of gender roles and relationship satisfaction for married and cohabiting couples, or are there different perceptions about gender roles relationships based on relationship status?

\section{Gender Role Relationships and Children}

Previous studies on views about gender role relationships and perceived satisfaction in marriage have not examined the effects of children on those views. Although studies of marital satisfaction over 
time have reported a decline in satisfaction when children are in the home (Cox, Paley, Burchinal, \& Payne, 1999; Crohan, 1996; Gable, Belsky, \& Crnic, 1995; Hackel \& Ruble, 1992; Lawrence, Nylen, \& Cobb, 2007; Lawrence, Rothman, Cobb, Rothman, \& Bradbury, 2008; Umberson, Williams, Powers, Chen, \& Campbell, 2005; Van Laningham, Johnson, \& Amato, 2001; Waite \& Lillard, 1991; Wallace \& Gotlib, 1990), it is not known if emerging adults believe that the satisfaction of married couples enacting varying GRRs are differentially affected by the presence of children. In addition, no studies have been found in which the effects of parental status of cohabiting couples on the satisfaction of couples enacting varying GRRs have been examined. Therefore, in this study the presence or absence of children is an added independent variable.

\section{Purpose of the Current Study}

The primary purpose of this study was to examine emerging adults' views about satisfaction of various types of gender role relationships. Specifically, I examined respondents' views about the satisfaction of couples in male-head/female-complement, male-senior/female-junior, partner-equal, female-senior/male-junior, and female-head/male-complement gender role relationships. In addition, I examined anticipated personal satisfaction of the respondents if they were in such gender role relationships in the future. I also explored whether or not several individual and familial characteristics of emerging adults were related to their views about the vignette couple's satisfaction and anticipated relationship satisfaction in the five types of gender role relationships. Finally, I examined the effects of varied marital statuses and parental statuses of couples in diverse gender role relationships on views about the couple's satisfaction and anticipated personal satisfaction. The following research questions were answered: 
Research question 1a. Do emerging adults' views about satisfaction in couple relationships differ depending on gender role relationship type: male-head/female-complement, male-senior/female-junior, partner-equal, female-senior/male-junior, and female-head/male-complement gender role relationships?

Research question 1b. Does emerging adults' anticipated personal satisfaction in couple relationships differ depending on gender role relationship type: male-head/female-complement, malesenior/female-junior, partner-equal, female-senior/male-junior, or female-head/male-complement gender role relationships?

Research question 2a. Which of the following respondent characteristics are related to views about satisfaction in the five types of gender role relationships: Gender, education, religiosity, annual family income, and/or parents' marital status?

Research question $\mathbf{2 b}$. Which of the following respondent characteristics are related to anticipated personal satisfaction in the five types of gender role relationships: Gender, education, religiosity, annual family income, and/or parents' marital status?

Research question 3a. Do emerging adults' views about satisfaction differ between married and cohabiting couples in different gender role relationships?

Research question 3b. Does emerging adults' anticipated personal satisfaction differ between married and cohabiting couples in different gender role relationships?

Research question 4a. Do emerging adults' views about satisfaction differ between couples with children and couples without children in different gender role relationships?

Research question 4b. Does emerging adults' anticipated personal satisfaction differ between couples with children and couples without children in different gender role relationships?

\section{Advantages and Disadvantages to the Methodologies used in Prior Studies}


Gender role relationship typologies. A majority of the studies on expectations of future gender role relationships have conceptualized GRRs as either traditional or egalitarian, without taking notice of the many idiosyncrasies that lie within and beyond these two types of relationships. Cobb et al. (2003) identified four types of GRRs, but did not include a fifth that is necessary in order to complete the partner dyad gender role continuum. The current study adopts five descriptions of GRRs as categories of the independent variable, thereby extending the literature on types of gender role relationship arrangements in heterosexual romantic relationships.

Inclusion of predictor variables. Although some researchers have examined individual and family level factors that may be related to gender role expectations in marriage and cohabiting relationships, these variables have not been assessed in relation to emerging adults' views of couple satisfaction and anticipated satisfaction with different types of gender-role divisions of responsibilities. This is a gap that the current study attempts to fill by examining how the variables of respondents' gender, education level, religiosity, annual family income, and parents' marital status are related to the relationship between gender role relationships and views about satisfaction. Because the sample is comprised of nevermarried and child-free emerging adults, a group that is often self-focused, free of adult obligations, and typically does not have an income separate from their parents (Arnett, 2004), the income level of their family of origins will be used as the annual family income variable. It is expected that familial characteristics will be related to views about gender role satisfaction because socialization theories suggest that experiences in childhood and young adulthood help shape the characteristics that one considers ideal in a potential partner as well as one's attitudes toward marriage roles (Bandura, 1977). Because parents primarily guide children's experiences and, while doing so, practice and espouse their attitudes and values, it is posited that gender role attitudes, and therefore views about satisfaction, are transmitted from one generation to the next (Moen, Erickson, \& Dempster-McClain, 1997; Thornton et al., 1983). 
Methods of data collection. The majority of the studies in this area have used open-ended questions and Likert-scale responses to assess gender role expectations. Although "vignettes provide a valuable technique for exploring people's perceptions, beliefs and meanings about specific situations" (Barter \& Renold, 1999, p. 4), their use has been generally overlooked in the study of this topic. "Vignettes are simulations of real events which can be used in research studies to elicit subjects' knowledge, attitudes or opinions according to how they state they would behave in the hypothetical situation depicted" (Gould, 1996, p. 207). Researchers have found that when presented with a vignette, respondents often react to the characters' behaviors with strong emotions (Ganong \& Coleman, 2006), and suggestions about what characters should do are related to what individuals would do if actually presented with the situation (Sutton, 1998). Focusing on attitudes and asking respondents about what hypothetical vignette characters should do in a given situation, rather than asking them what they would do, also yields less guarded responses because the scenario is perceived as less personally threatening and distances respondents from their own relationship practices (Finch, 1987).

Vignettes are often used in experimental designs to study many social phenomena (Ganong \& Coleman, 2006; Rossi \& Nock, 1982). In this method of data collection, respondents are presented with a brief multidimensional description of a person or an event in which the researcher randomly manipulates levels of independent variables, such as the sex of the characters (Rossi \& Berk, 1997; Rossi \& Nock, 1982; Rossi \& Rossi, 1990). The researcher is then able to examine how these manipulations affect respondents' responses to subsequent questions about their attitudes, beliefs, or judgments concerning the events portrayed in the vignette.

Advantages to using vignettes as a method of data collection. The use of questionnaires and researcher observation as data collection techniques sometimes fall short when the goal is to explore how individuals might respond to a particular scenario. Hughes and Huby (2002) conclude that "vignettes... 
can be valuable research tools in the study of people's lives, their attitudes, perceptions and beliefs" (p. 385). Vignettes are useful research tools in the study of rare events or those that do not vary much in the real world context, in topic areas that are difficult to examine, in situations that present ethical concerns, when studying variables that are difficult to assess, and when data collection of naturally-occurring behaviors is costly (Ganong \& Coleman, 2006; Ludwick, Wright, Zeller, Dowding, Lauder, \& Winchell, 2004).

Vignettes can also be used in combination with qualitative methods. After obtaining force-response data, researchers have the opportunity to use open-ended questions to assess respondents' rationale for responding in a particular way. Combining quantitative and qualitative data collection techniques gives the researcher insight into the statistical findings by helping them interpret the results (Ganong \& Coleman, 2006). Additionally, the open-ended nature of qualitative questions may elicit responses that help direct the researcher into new topic areas or variables that could be explored in future studies.

Vignettes have been used to measure gender role ideology. Kroska (2000) used a series of vignettes depicting men and women engaging in a variety of work, marital, family, and societal roles to determine the gender ideology of middle-aged adults. Later, Pedersen (2010) developed vignettes based on those in Kroska's (2000) study to determine the gender ideology in a sample of college-aged students. Both researchers considered the use of vignettes advantageous. Kroska claimed that vignettes provide a "valid alternative to gender attitude scales" (p. 382) and that they "may be a viable strategy for standardizing the meaning of gender in family (and other) contexts" (p. 385). The current study takes advantage of these qualities by utilizing the vignette as a data collection method. 


\section{CHAPTER 2: METHODS}

\section{Sampling}

The current study included 451 males and females between the ages of 18 and 29 in order to capture the full range of ages that are considered to be emerging adulthood (Arnett, 2004). Emerging adults are often self-focused and free of adult obligations, such as marriage, children, and a career, making their perspective of gender role relationships relatively unbiased by direct personal experience. Therefore, never-married and child-free individuals who were able to read and understand English were included in the sample, and emerging adults who were married, had children, or were cohabitating with a partner were excluded. Recruitment flyers and online advertisements were used to recruit participants. MU instructors were asked to post a description of the study, my contact information, and an online link to the study on course websites to recruit students (see Appendix A for the recruitment flyer posted on course websites). Additionally, I distributed the same recruitment flyer electronically via academic and professional listserves (e.g., Family Science, and Feminist and Family Studies sections of NCFR) and other social networks (e.g., Facebook, Craigslist).

\section{Data Collection}

Respondents were directed to an online data collection website (i.e., surveymonkey.com). After reading an informed consent page, which briefed them on the purpose of the research and the risks and benefits of participating (see Appendix B for the informed consent/cover letter document), respondents were presented with an online questionnaire that asked them to report on a series of demographic questions. They then were randomly assigned to one of 20 versions of a vignette that described a hypothetical couple. The couple was portrayed as either married with children, married without children, cohabitating with children, or cohabitating without children and as fitting one of the five gender role 
arrangements. After reading the vignette, respondents were asked to rate their views about the couple's relationship satisfaction and their anticipated personal satisfaction if they were in the relationship.

\section{Measures}

Demographic questionnaire. A self-report demographic questionnaire was used to assess individual and familial characteristics of the respondents (see Appendix $\mathrm{C}$ for the demographic questionnaire). Specifically, gender, sexual orientation (i.e., heterosexual, gay/lesbian, or bisexual), years of education (i.e., 11 or fewer, 12, 13, 14, 15, 16, or 17 or more), race (i.e., White, Black or African American, Native American or Alaska Native, Asian, Native Hawaiian or Other Pacific Islander, or Other), ethnicity (i.e., Non-Hispanic or Latino, or Hispanic or Latino), religiosity (i.e., not religious at all, slightly religious, moderately religious, or very religious), and relationship status (i.e., not dating, dating casually, dating one person exclusively but not living together, or engaged but not living together) were collected. Further, data on the familial characteristics of parents' marital status, annual family income (i.e., less than $\$ 20,000, \$ 20,000-\$ 39,999, \$ 40,000-\$ 59,999, \$ 60,000-\$ 79,999, \$ 80,000-\$ 99,999, \$ 100,000$ $\$ 149,999, \$ 150-\$ 199,999$, or $\$ 200,000$ or more), father's and mother's employment status (i.e., did not work in paid employment, worked part-time, or worked full-time), and father's and mother's education level (i.e., less than a high school diploma, high school diploma or GED, two-year college degree, fouryear college degree, or graduate degree) were collected.

Vignettes. The current study had three independent variables, type of gender role relationship (i.e., male-head/female-complement, male-senior/female-junior, partner-equal, female-senior/male-junior, and female-head/male-complement), marital status (i.e., married or cohabitating), and parental status (i.e., child-present or child- absent). Appendix D illustrates the 20 hypothetical relationship variations.

Establishing adequate validity to the measurement is a critical prerequisite for any data collection method. To establish internal validity of vignettes, Flaskerud (1979) advocated for three criteria: 
developing vignettes from existing literature or using case histories of real people, submitting the vignettes to a panel of experts for comment, and pre-testing to weed out ambiguous questions. To ensure respondents' understanding and belief of content, researchers also advise that vignettes must be clearly and concisely written and structured with plausible content and portrayal of events (Finch, 1987; Ganong $\&$ Coleman, 2006). These precautions were followed in the current study to ensure that vignettes accurately portrayed the two different marital statuses, the two different parental statuses, and the five different types of gender role relationships. Specifically, several established researchers and graduate students reviewed and critiqued the content and face validity of the vignettes. Suggestions for improvement were used to revise the scenarios to ensure that they accurately portrayed the relationships that they attempted to depict.

Perceived relationship satisfaction. The dependent variables in the current study were: (1) respondents' views about how satisfied they thought the relationship was for the couple portrayed in the vignette and (2) anticipated personal satisfaction if the respondent was in the relationship described. Perceived satisfaction was assessed using an adapted version of the Marital Opinion Questionnaire (Huston, McHale, \& Crouter, 1986). This measure contains 11 semantic differential items to assess specific aspects of relationship satisfaction (e.g., miserable/enjoyable, interesting/boring) on a scale of 1 to 7 (see Appendix E for the perceived relationship satisfaction measure). Additionally, an item that assessed perceived global satisfaction of the couple on a semantic differential scale of 1 (very dissatisfied) to 7 (very satisfied) was presented. These 12 items were averaged to create a composite score of perceived satisfaction, the Couple Satisfaction Semantic Differential (CSSD), with higher scores indicating greater perceived relationship satisfaction. Finally, an item that assessed anticipated personal satisfaction if the respondent was in the relationship described (Anticipated Personal Satisfaction; APS) was presented on a 7-point scale $(1=$ very dissatisfied; 7 = very satisfied $)$. Respondents were asked about both the vignette 
couples' and their own anticipated relationship satisfaction to assess respondents' views about gender roles in general and gender roles in a more personal sense. Although it was expected that the scores on the CSSD and APS would be correlated because individuals tend to project themselves into vignette situations (Ganong \& Coleman, 2006), there also could be variability in the way that respondents think about others' satisfaction with a given situation and their own satisfaction with the same situation.

Open-ended questions were used to ask respondents to provide a rationale for their forced-choice answers concerning the satisfaction that they attributed to each scenario. Specifically, respondents were given an unlimited space to explain their answers to the following: "Please explain why you rated the couples' satisfaction this way," and "Please explain why you rated your own satisfaction this way." Ganong and Coleman (2006) suggested that open-ended questions used in this context were "similar to the validity checks that are sometimes conducted in laboratory experiments to ascertain whether the participants attended to the experimenter-manipulates independent variables" (p. 459). These questions also provide a glimpse into how respondents interpreted the vignette, why they answered the quantitative portion the way they did, and what variables require additional attention in future research.

\section{Data Analyses}

Research questions 1, 3, and 4. Research questions (RQ) 1a, 1b, 3a, 3b, 4a, and 4b were examined using 5 (gender role relationships [GRR]) by 2 (marital status) by 2 (parental status) betweengroups multivariate analysis of variance (MANOVA). Significant effects were followed with betweengroups analysis of variance (ANOVA) tests. The CSSD scores (views about the couple's satisfaction) and APS scores (anticipated personal satisfaction) served as dependent variables in these analyses.

Research question 2. Hierarchical multiple regressions were conducted to answer RQs $2 a$ and $2 b$. Vignette couple's marital and parental statuses were entered first in the models as controls, followed by individual and familial demographic characteristics as predictor variables. 
Qualitative data. Data obtained from the respondents' answers to the open-ended questions were coded and analyzed using content analytic methods (Budd, 1967). Specifically, using the language of respondents, each separate reason was categorized into meaningful and pertinent units of information on a variety of levels (e.g., words, phrases, concepts, and themes). Then, each category was quantified across all responses by their number of occurrences and each coded category was used to identify patterns in the way in which respondents developed their opinion regarding perceived relationship satisfaction level. Finally, the presence of these patterned responses that emerged from the coded responses was used to help interpret the quantitative findings.

\section{Sample}

A total of 451 respondents completed the online questionnaire. The respondents ranged in age from 18 to 29 years with a mean (SD) of 21.88 (3.12), and were over-representatively female (86.2\%). The majority of the respondents were also White (86.6\%), non-Hispanic (94\%), heterosexual (94.4\%), had parents who were married when they were children (73.2\%), and had a father and mother who worked full-time the majority of their childhood years $(95.1 \%$ and $55.8 \%$, respectfully). The majority of the respondent's fathers and mothers also had an education beyond a high school diploma or GED. The sample had higher education levels than the general public (U.S. Census Bureau, Current Population Survey, 2011 Annual Social and Economic Supplement, Table 1,2011); while the majority had a high school diploma/ GED (8.9\%) or some college without an earned degree (47.9\%) as their highest level of education, a large percentage had either an earned university (four-year) degree (18.2\%) or at least some graduate school education (25.1\%). Twenty percent of the sample were "not religious at all," $26 \%$ were "slightly religious," 36\% were "moderately religious," and 18\% were "very religious." They also represented a wide array of total annual family income levels, ranging from less than $\$ 20,000$ to $\$ 200,000$ or more. See Table 1 for sample distributions. 
Ninety-two (20.4\%) of the respondents were randomly assigned to the male-head/female complement GRR, 81 (18.0\%) to the male-senior/female-junior GRR, 83 (18.4\%) to the partner-equal GRR, 92 (20.4\%) to the female-senior/male-junior GRR, and 103 (22.8\%) to the female-head/malecomplement GRR. Two-hundred thirty-seven (52.5\%) were randomly assigned to read about an unmarried couple, while 214 (47.5\%) responded to a married couple. Two-hundred thirty-seven (52.5\%) were randomly assigned to read about a couple without children, while 214 (47.5\%) responded to a couple with children. Table 2 shows the descriptive statistics and inter-correlations among the study variables. Table 3 shows the means and standard deviations of the CSSD and APS by GRR, marital status, and parental status. 


\section{CHAPTER 3: RESULTS}

\section{Results of Quantitative Data}

MANOVA and follow-up test results. Initially, 5 (gender role relationships [GRR]) X 2 (marital status) X 2 (parental status) multivariate analysis of variance (MANOVA) tests were run to test RQs 1a, $1 \mathrm{~b}, 3 \mathrm{a}, 3 \mathrm{~b}, 4 \mathrm{a}$, and $4 \mathrm{~b}$ with respondents' views about satisfaction of the vignette couple's relationship, as measured by the CSSD, and anticipated personal satisfaction if they would be in such a relationship, as measured by the APS, as the dependent variables (see Table 4). Results of the MANOVA indicated that there were significant multivariate main effects for GRR, Wilks' Lambda $(8,836)=.91, p=.00$ and for marital status of the vignette characters, Wilks' Lambda $(2,417)=.94, p=.00$. The main effect of parental status was not significant, Wilks' Lambda $(2,417)=1.00, p=.61$. There were no significant interactions effects (RQs 3a, 3b, 4a, and 4b; see Table 4).

Significant MANOVA findings were followed by univariate analysis of variance tests (ANOVAs) and post-hoc analyses. For the main effect of GRR, the ANOVA showed significant GRR effects on respondents' views about the vignette couple's relationship satisfaction (RQ1a), F $(4,434)=8.56, p=.00$, and on the respondents' anticipated relationship satisfaction (RQ1b) if they were in the type of relationship described in the vignette to which they were assigned, $\mathrm{F}(4,434)=7.28, p=.00$ (see Table 5). Tukey HSD mean difference test revealed that respondents rated the couple's relationship satisfaction and their anticipated personal satisfaction significantly higher when they were exposed to the partner-equal GRR than when they were exposed to any other type of GRR (see Tables 6 and 7). There were no significant differences between any of the other GRRs.

Results of the ANOVA for the significant main effect for marital status showed that respondents rated the couple's relationship satisfaction significantly higher when they were described as being married than when they were described as having a cohabitating, unmarried relationship, $\mathrm{F}(1,437)=6.56, p=.01$ 
(see Table 5). There also was a significant main effect for marital status on the respondents' anticipated relationship satisfaction for themselves if they were in same type of relationship as the vignette to which they were assigned, $\mathrm{F}(2,436)=28.10, p=.00$. Respondents rated their anticipated personal satisfaction significantly higher when exposed to the marital relationship than when exposed to the cohabitating, unmarried relationship.

Hierarchical regressions and follow-up test results. Ten hierarchical regression models were conducted to answer RQs $2 \mathrm{a}$ and $2 \mathrm{~b}$, which asked if respondent's gender, education, religiosity, annual family income, and/or parents' marital status were related to their views about relationship satisfaction in the five types of GRRs. These individual and familial demographic characteristics of the sample served as predictor variables in the multiple regression models. The sample was subset by the five GRRs, producing five individual subsamples. CSSD served as the criterion variable for five regression models (RQ 2a). A similar approach was taken to address RQ2b, with the APS serving as the criterion variable in the other five models. In all of the analyses, step 1 consisted of entering marital status and parental status of the hypothetical couple as controls. Step 2 of the regression analyses consisted of entering in the respondents' gender, education, religiosity, annual family income, and parental marital status. These variables were entered into the equation at this step so that their potential moderating effects of the relation between GRR and relationship satisfaction could be tested.

Male-head/female-complement. For the male-head/female-complement GRR, respondent's annual family income was significantly and positively related to CSSD scores, $\beta=.30, t(81)=2.52, p=.01$ (see Table 8). The higher the respondents' family incomes, the more likely they were to perceive greater relationship satisfaction in male-head/female-complement GRRs. None of the other variables in this regression were significant. 
None of the demographic characteristics of the respondents were significantly related to anticipated personal satisfaction in male-head/female complement GRRs. The control variables of the vignette couple's marital status and parental status were significantly and positively related to APS scores, $\beta=.26, t(87)=2.51, p=.01$ and $\beta=.21, t(87)=2.04, p=.05$, respectively (see Table 8). These findings suggest that respondents exposed to the male-head/female-complement GRR anticipated greater satisfaction for themselves when the portrayed couple was married than when cohabiting, and when the portrayed couple had children than when they did not have children.

Male-senior/female-junior. The regression model for the male-senior/female-junior GRR revealed that respondent's education level was significantly and negatively related to $\operatorname{CSSD}, \beta=-.27, t(68)=-$ 2.03, $p=.05$ (see Table 9). The lower the level of respondents' attained education, the more likely they were to perceive greater couple relationship satisfaction in male-senior/female-junior GRRs. No other variables in this regression were significant.

Respondent's gender and education level were significantly and negatively related to APS, $\beta=$ $.28, t(72)=-2.60, p=.01$ and $\beta=-.24, t(72)=-2.18, p=.03$, respectively. Male respondents anticipated being more personally satisfied in a male-senior/female-junior GRR than did females. The lower the level of respondents' attained education, the more likely they were to anticipate being personally satisfied in the male-senior/female-junior GRR. None of the other demographic variables in this regression were significant. The control variable of vignette couple's marital status was significantly and positively related to APS, $\beta=.40, t(77)=3.78, p=.00$ (see Table 9). The male-senior/female-junior GRR was viewed as more personally satisfying when the portrayed couple was married than when they were cohabiting.

Partner-equal. The regression model for the partner-equal GRR showed that no demographic characteristics of the respondents were significantly related to CSSD or APS (see Table 10). The regression model that examined the predictors of anticipated personal satisfaction revealed that the control 
variable of vignette couple's marital status was significantly and positively related to APS, $\beta=.28, t(78)=$ 2.61, $p=.01$ (see Table 10). The partner-equal GRR was anticipated to be more personally satisfying when the portrayed couple was married than when they were cohabiting.

Female-senior/male-junior. For the female-senior/male-junior GRR, respondent's religiosity was significantly and negatively related to CSSD, $\beta=-28, t(79)=-2.70, p=.01$ (see Table 11). The more religious respondents were, the less likely they were to perceive female-senior/male-junior GRRs to have higher relationship satisfaction. No other variables in this regression were significant.

The regression model for the female-senior/male-junior GRR and APS revealed that respondents' religiosity and respondents' annual family income were significantly and negatively related to anticipated personal satisfaction, $\beta=-.37, t(80)=-3.92, p=.00$ and $\beta=-.25, t(80)=-2.39, p=.02$, respectively. The more religious respondents were and the higher family incomes respondents had, the less likely they were to anticipate having greater personal satisfaction in a female-senior/male-junior GRR. None of the other demographic variables in this regression were significant. The control variable of vignette couple's parental status was significantly related to APS, $\beta=-.26, t(85)=-2.51, p=.01$ (see Table 11). The female-senior/male-junior GRR was anticipated to be more personally satisfying when the couple did not have children than when children were present.

Female-head/male-complement. The regression model for the female-head/male-complement GRR showed that no variables were significantly related to CSSD (see Table 12). The regression model that tested the relationship for the female-head/male-complement GRR revealed that respondent's religiosity was significantly and negatively related to APS, $\beta=-.36, t(87)=-3.49, p=.00$ (see Table 12). The more religious respondents were, the less likely they were to anticipate having greater personal satisfaction in a female-head/male-complement GRR.

\section{Results of Qualitative Data}


The data obtained from the respondents' answers to the open-ended questions (i.e., "Please explain why you rated the couples" satisfaction this way," and "Please explain why you rated your own satisfaction this way") were coded using content analytic methods (Budd, 1967), resulting in a total of 26 codes. Table 13 contains the complete list of codes derived from respondents' explanations.

Rationale for couple's satisfaction responses. The majority of respondents $(\mathrm{N}=421)$ provided a rationale for their views about the vignette couple's relationship satisfaction (i.e., CSSD). The most common rationale was a negative perception about the vignette couple that was based on the respondents' preferences or experiences $(\mathrm{N}=276)$. This code represents individuals who brought specific attention to the negative aspects of the couple depicted in the vignette. An example comes from a respondent assigned to the cohabitating, child-present, male-head/female-complement GRR, "My parents were in a similar "'traditional"" marriage (although my mom also worked full-time). The model that I grew up with never sat well with me, and I would prefer to do things differently."

The second most common rationale given was a personal desire for an equal-partner GRR regarding work, decision-making, and household tasks $(\mathrm{N}=194)$. An example of this code comes from a respondent assigned to the cohabitating, child-present, male-senior/female-junior GRR, "I want an equal. I want family decisions to be made by both partners. If I have children, I want both partners to be active and influential."

The third most frequently given reason for their rating of the couple's relationship satisfaction was that they projected happiness, strength, and/or functionality onto the vignette couple because there was no mention in the vignette that the couple was not satisfied with the relationship $(\mathrm{N}=140)$. An example comes from a respondent assigned to the cohabitating, child-present, female-senior/male-junior gender role relationship, "It seems that they have a good income and children together so they seem very satisfied." 
Rationale for anticipated satisfaction responses. The majority of the respondents $(\mathrm{N}=413)$ also provided a rationale for their anticipated personal relationship satisfaction if they were in the type of relationship described in the vignette (i.e., APS). Generally, respondents gave similar types of explanations for their perceptions of the vignette couple's relationship satisfaction (see Table 14) as they did for their anticipated relationship satisfaction if they were in the type of relationship described in the vignette (see Table 15). Like the CSSD explanations, the most common rationale given by respondents was that they negatively related the couple to their own life desires and/or experiences $(\mathrm{N}=296)$. Again, the second most common rationale given was a personal desire for an equal-partner GRR regarding work, decision-making, and household tasks $(\mathrm{N}=192)$. The third most frequently reported rationale was a positive perception about the vignette couple, based on the respondents' preferences or experiences $(\mathrm{N}=$ 91). A respondent assigned to a married, child-absent, female-head/male-complement gender role relationship provides an example, "I've seen my parents do it for years, and it's worked out fine."

Gender role relationship. Tables 14 and 15 show the qualitative rationales for the CSSD and APS, respectively, given by respondents based on their gender role relationship assignment. These tables show that respondents in each GRR assignment tended to cite similar patterns of explanations for their views about the vignette couple's relationship satisfaction (i.e., CSSD) and their anticipated relationship satisfaction if they were in the type of relationship described in the vignette (i.e., APS). Although the distributions of coded responses for each GRR assignment were similar across the two sets of rationale, there are a few noteworthy findings.

First, quite a few respondents saw strengths in all five GRR types, but the partner-equal GRR was viewed most positively. For example, the codes "positively relating the scenario to own desires or experiences," "projecting happiness/strength/functionality," and "presence of a successful career" were common. Moreover, fewer respondents reported a negative view of the partner-equal GRR than other 
GRR types (see Tables 14 and 15 for the distribution of the codes: "negatively relating the scenario to own desires or experiences," "projecting conflict/dysfunction/stress on the couple," "emasculation in nonconventional GRRs," "power imbalance among the spouses," and "projecting laziness on partner not working"). A respondent assigned to the partner-equal GRR provides an example, "Couples who share responsibilities for both income production and childcare may be more satisfied because they have more common responsibilities. Rigid gender roles may tend to increase conflict over time." Overall, the qualitative data corroborate the quantitative data in suggesting that emerging adults view egalitarian GRRs to be the most satisfying both in general and personally.

Second, more respondents assigned to the partner-equal GRR than any other GRR commented about "work-personal life balances," and that the "GRR is too boring/consistent/rigid". For example, a respondent assigned to the partner-equal GRR wrote, "I am assuming that they do not spend a desirable amount of time together due to the nature of their employment. Under the assumption that there is not much flexible free time in this relationship due to work obligations."

Third, the second most frequent code for both of the satisfaction measures was "preference for an equal-partner GRR.” This was a reason given more often when male- or female-superior GRRs were portrayed than when equal partners were portrayed. This finding suggests that being exposed to conventional and nonconventional GRRs elicits specific thoughts about which types of GRRs are the most fulfilling, and that respondents are most likely to report a preference for a specific GRR when they are exposed to one that they do not find as fulfilling.

Fourth, respondents assigned to the nonconventional (i.e., female-senior/male-junior and femalehead/male-complement) GRR types were more likely to bring attention to the following codes: "emasculation in nonconventional GRRs," "preference for a nonconventional GRR," and, interestingly, "preference for a conventional GRR." This finding suggests that being exposed to a nonconventional GRR 
elicits specific thoughts about which types of gender role relationships are the most fulfilling, and respondents may weigh the alternatives more often when they are exposed to nonconventional GRRs as opposed to conventional GRRs.

Marital status. Tables 16 and 17 show the qualitative rationales for the CSSD and APS, respectively, given by respondents based on their marital status assignment. The tables show that the distributions of coded responses for both married and cohabitating assignments were generally similar across the two sets of rationale. However, there were two codes in which respondents assigned to the married couple and those assigned to the cohabiting couple differed. Those assigned to the married couple were more likely to report having a "preference for a conventional GRR" and less likely to report having a "negative view of cohabitation." An example of the later code appears in the quote, "I was raised in a good family, married parents so of course I would marry." This finding supports the quantitative results, which suggest that respondents view married couples to be more satisfied than unmarried, cohabitating couples.

Parental status. Tables 18 and 19 show the qualitative rationales for the CSSD and APS, respectively, given by respondents based on their parental status assignment. Again, the distributions of coded responses for both child-present and child-absent assignments were similar across the two sets of rationale. The coded responses reflect the lack of significance on the quantitative analyses regarding the influence of parental status on emerging adults' views about relationship satisfaction. The only difference between those assigned to the child-present and child-absent was the distribution of those who cited a "negative view of child-free couples." Those assigned to the child-absent couple were more likely to report such views, illustrated by the quote, "They have no children and have the same routine. There would be no excitement and no fun."

Summary. The majority of respondents related the scenario to their personal lives; however, respondents were far more likely to negatively relate the scenario to their lives than to relate it positively. 
The qualitative data were generally supportive of the quantitative findings. The partner-equal GRR was viewed most positively. Further, those assigned to the unmarried, cohabitating couple were more likely to cite having a negative view of cohabitation, which indicates that respondents viewed married couples to be more satisfied than unmarried couples. Lastly, those assigned to the child-absent couple were more likely to cite having a negative view of child-free couples, which indicates that respondents may view parents to be more satisfied than non-parents. 


\section{CHAPTER 4: DISCUSSION}

\section{Perceptions of Relationship Satisfaction across Types of Gender Role Relationships}

A primary goal of the current study was to understand which gender role relationships emerging adults viewed to be the most satisfying. Emerging adults rated the vignette couple's relationship satisfaction significantly higher when the couple was described as having an egalitarian GRR than when they were described as having any other type of GRR. The respondents also anticipated being more personally satisfied in an egalitarian GRR than in any other GRR type. These findings are consistent with prior research that suggests there has been a general move toward acceptance of egalitarian gender roles in the past couple of decades (Bolzendahl \& Myers, 2004; Brewster \& Padavic, 2000; Cichy et al., 2007; Thornton \& Young-DeMarco, 2001; Zuo \& Tang, 2000). Further, the findings support Cobb et al.'s (2003) finding that emerging adults perceived egalitarian GRRs to be more satisfying than more conventional, as well as more nonconventional, couple gender role divisions.

Egalitarian relationships may be viewed as more appealing and satisfying than other types of partnerships because both partners are seen as equally contributing to household duties, household income, and family decision-making. Emerging adults in this study may have attributed less conflict and more happiness in egalitarian couples than in couples with other gender role types because of the perceived fairness of household workload distribution and the lack of power differences between partners. In fact, when respondents were given the opportunity to explain why they rated the couple's relationship satisfaction and their anticipated personal satisfaction the way they did via open-ended questions, many expressed positive views of partner-equal relationships, projecting happiness, strengths, and greater functionality to those relationships. The majority of respondents commented on their desires to have an egalitarian romantic relationship in their own lives, marked by equal time spent in housework and paid work, as well as equal power, decision-making, and mutual respect. Although emerging adults also 
perceived the possibility of negative dimensions of such relationships (i.e., the lack of shared interests, boredom, rigidity), more respondents across the GRRs expressed a preference for an egalitarian GRR than for either a conventional GRR (i.e., male-head/female-complement, male-senior/female-junior) or a nonconventional GRR (i.e., female-head/male-complement, female-senior/male-junior). Many respondents also expressed beliefs that in head/complement or senior/junior relationships the partner working full-time might resent or project laziness on his or her partner. Further, many indicated that conventional and nonconventional GRRs do not allow for financial independence of the junior or complement partner. Some also explained that they rated relationship satisfaction low in nonconventional dyads because this type of partnership is not generally accepted by society and it would make the male partner feel emasculated because he was not fulfilling his socially-expected obligation to be the main provider for the family.

\section{Personal Characteristics related to Perceptions of Relationship Satisfaction across types of Gender Role Relationships}

In this study, I examined how the variables of respondents' gender, education level, religiosity, annual family income, and parents' marital status were related to views about couple satisfaction in different gender role relationships. Views about satisfaction of couples in the male-head/femalecomplement GRR was positively related to family income. Views about satisfaction of couples in the male-senior/female-junior GRR was negatively related to levels of education. Views about satisfaction of couples in the female-senior/male-junior GRR was negatively related to religiosity. Views about couple satisfaction in the egalitarian and the female-head/male-complement GRRs were not related to any of the demographic variables examined. The same personal characteristics were examined in relation to emerging adults' anticipated personal satisfaction if they were in type of GRR described. Anticipated personal satisfaction in the male-senior/female-junior GRR was negatively related to gender and to levels 
of education. Anticipated personal satisfaction in the female-senior/male-junior GRR was negatively related to religiosity and income. Anticipated personal satisfaction of the female-head/male-complement GRR was negatively related to religiosity. Anticipated personal satisfaction of the male-head/femalecomplement and the egalitarian GRRs were not related to any of the demographic variables examined.

Gender. The absence of gender differences in views about couple's relationship satisfaction across different GRRs, coupled with men's higher ratings than women of their anticipated personal satisfaction with the male-senior/female-junior GRR, suggests that men may recognize, in the abstract, that egalitarian relationships have certain advantages for both partners (e.g., fairness, income), but they also recognize how they may personally benefit from a male-superior relationship (e.g., more power). Men did not, however, anticipate higher personal satisfaction than women with the other conventional GRR (i.e., malehead/female-complement). This may be because men may realize the advantages to having a dual-income household but still want to maintain the role as the family's primary breadwinner, and so they prefer to have their partner work outside of the home as a junior breadwinner. This finding partially supports previous research that has shown that men tend to hold more conventional gender role attitudes than women (Bolzendahl \& Myers, 2004; Brewster \& Padavic, 2000; Bryant, 2003; Cichy et al., 2007; Mickelson et al., 2006; Pearce \& Thornton, 2007; Powers et al., 2003; Thornton \& Young-DeMarco, 2001; Zuo \& Tang, 2000). Earlier studies that assessed future relationship expectations suggest that most college men expected to be in conventional GRRs as adults - working more hours in paid employment than their partners (Kaufman, 2005), spending less time in domestic and parenting roles than partners (Ganong \& Coleman, 1992; Ganong et al., 1996; Kaufman, 2005), being more professionally successful, making more money, and in other ways having advantages in comparison to their future female partners (Ganong \& Coleman, 1992; Ganong et al., 1996). Ganong and Coleman (1992; Ganong et al., 1996) found that women expected to be in such conventional GRRs as well, and that appears to have changed. Young 
women's preferences for egalitarian relationships, at both the abstract and personal levels, is not surprising, given the gains in labor distribution, power sharing, and decision-making opportunities that egalitarian relationships hold for them.

Prior research also suggests that men's gender role attitudes have changed at a less rapid rate than women's attitudes; albeit, men are still becoming more positive in their views of egalitarianism (Myers \& Booth, 2002). The finding that gender only predicted anticipated personal satisfaction of one of the GRRs gives evidence that men's and women's views of satisfaction in GRRs are converging, but they are not yet the same. It may be that men simply need more time and experience with egalitarian GRRs before they reach women's level of acceptance. As this happens, men may begin to place less relevance on playing the role of the family's primary breadwinner and more on sharing household responsibilities, in turn continuing to decrease the gender gap in gender ideology in the future.

Education. The lower the level of respondents' attained education, the more likely they were to perceive greater relationship satisfaction both generally (i.e., among couples) and personally in malesenior/female-junior GRRs. Numerous studies have suggested that increased education level is positively related to egalitarian gender role beliefs (Bolzendahl \& Myers, 2004; Brewster \& Padavic, 2000; Bryant, 2003; Cunningham et al., 2005; Fan \& Marini, 2000; Kulik, 2002; Marks et al., 2009; Tallichet \& Willits, 1986), and may be explained by the notion that while exposing individuals to egalitarian ideas, educational attainment challenges traditional myths and stereotypes about the way in which men and women can engage in gender roles (Cassidy \& Warren, 1996; Davis \& Robinson, 1991; Rhodebeck, 1996). Researchers predict that as graduation rates continue to rise, like they have in recent decades, more and more people will be exposed to the liberalizing effects of education, and more and more people will be accepting of and practicing egalitarian gender roles (Brewster \& Padavic, 2000). Education, however, did not play a role in emerging adults' views about satisfaction with the other conventional GRR. It may be 
that, in today's world, emerging adults realize that it is difficult to support a family with a single income, especially if the male partner does not have a high level of education, and so still prefer a traditional GRR but one with both partners contributing to paid employment.

Religiosity. The more religious emerging adults were, the less likely they were to anticipate having greater personal satisfaction in both of the nonconventional GRRs, and the less likely they were to perceive greater relationship satisfaction of couples in the female-senior/male-junior GRR. Rather than assessing the type of religion that respondents adhered to, religiosity was used to measure the level of importance that religion played in the lives of respondents. Although these are related constructs, they are separate measures (Kirkpatrick, Hood, \& Hartz, 1991). Many religions promote and reinforce traditional gender beliefs and strong religious affiliation is related to traditional gender role beliefs (Bang et al., 2005; Leech, 2010; Pearce \& Thornton, 2007; Peek et al., 1991), so it is not surprising that more religious emerging adults would perceive traditional gender role relationships to be more satisfying than nontraditional relationships.

Income. The higher the respondents' family incomes, the more likely they were to perceive greater relationship satisfaction of couples in male-head/female-complement GRRs and the less likely they were to anticipate having greater personal satisfaction in a female-senior/male-junior GRR. A possible reason for this finding is that emerging adults with higher income levels have the financial freedom to allow them to have a one-income household, and they foresee that the average couple may be more satisfied in a relationship in which the male is the only breadwinner than one in which the female is. Nevertheless, this finding is not consistent with the only previously published study that has examined the potential moderating effect of income on the relation between perceptions about relationship satisfaction and GRR type. Marks et al. (2009) found that men and women who have higher income levels express more egalitarian gender role relationship beliefs, while individuals who have lower income levels hold more 
traditional gender role beliefs. The discrepancy between the current study's findings and those of Marks et al. could be explained due to differences in the ages of the respondents, their marital and parental statuses, and how income was measured. In their study, Marks et al. (2009) sampled married parents of adolescents, and used household income as the measure of income, whereas the sample in this dissertation consisted of unmarried young adults who did not have children and who reported their parents' household income. It is also possible that there is a curvilinear relationship between income and GRR beliefs, with those of both lower and higher income levels holding more traditional gender role beliefs than those of middle income levels.

Parents' marital status. Although it was expected that respondent's views of GRRs would be influenced by whether or not their parents were married during their childhood, parents' marital status was not related to general or personal views of relationship satisfaction across the types of GRRs. This was the first study that has assessed the potential moderating effect of family structure on the relation between views about relationship satisfaction and GRR type. However, this finding is consistent with findings from Coleman and Ganong (1984) that suggest that high school and college student's family structure of origin (i.e., intact, step, single-parent) is not associated with future marriage role expectations in the areas of decision-making, wage-earning, housekeeping, and childcare.

Summary. Examining how individual and family level variables are related to the relationship between GRRs and views about satisfaction is an important contribution to the literature because it shows that many of the same variables that are correlated with gender role relationship ideologies and/or expectations (i.e., education level, religiosity, income level) are also related to views about satisfaction in gender role relationships. It also shows that some personal characteristics (i.e., gender and parents' marital status) do not help predict perceived satisfaction of differing GRRs. Because gender and parents' marital status generally were not predictors of this relationship, it is assumed that both men and women, and those 
growing up with both married and unmarried parents, think similarly about satisfaction levels across the differing types of GRRs.

More importantly, understanding the predictors of emerging adults' perceived satisfaction of GRRs allows conclusions to be made about how widespread egalitarian beliefs are. The lack of predictors for the perceived satisfaction of egalitarian GRRs indicate that, regardless of many personal characteristics, the egalitarian GRR is viewed as the most satisfying type of GRR. This means that men and women of differing education levels, religiosities, and income levels think that egalitarian GRRs would be the most satisfying for themselves, as well as for others. Because most groups of emerging adults idealize egalitarian GRRs more than other gender role types, it is expected that egalitarian gender role relationships will become more and more accepted and sought after in the near future.

\section{Perceptions of Relationship Satisfaction in Marital and Nonmarital Relationships}

Emerging adults in the current study rated the couple's relationship satisfaction significantly higher when they were described as married than when they were described as cohabiting. Further, when projecting themselves into the relationship portrayed in the vignette, respondents rated their anticipated personal satisfaction significantly higher when they were exposed to a marital relationship than when they were exposed to a cohabitating, unmarried relationship.

Although one study suggests that married and cohabitating couples do not differ in relationship satisfaction (Willetts, 2006), findings from this study are in line with several other studies that have found greater relationship satisfaction and happiness in married couples than cohabitating couples (Brown, 2003; Brown \& Booth, 1996; Brown \& Kawamura, 2010; Nock, 1995). These findings are expected because cohabitation in the United States is less institutionalized than in other developed nations, such as France or Sweden (Heuveline \& Timberlake, 2004), which means that there are fewer norms to help guide partners and less social support (Nock, 1995). 
The couples in the vignettes were described as living together for five years. Perhaps this information contributed to the way in which couples' relationship satisfaction level was perceived. Respondents may have viewed the decision to cohabitate as an alternative to marriage, rather than perceiving cohabitation as part of the "courtship" process toward marriage. Long-term cohabitors are more stigmatized than married couples, and are perceived to be less committed to their partners than their married counterparts (Scanzoni, 1995). Not surprisingly, research has shown that relationship duration contributes to the couples' satisfaction level. Couples who cohabit longer often experience decreased relationship satisfaction as compared to married couples (Brown, 2003; Brown \& Booth, 1996). This could be explained by a lack of commitment to the relationship and a lack of social support from family and friends to carry on the cohabitating, unmarried partnership.

Respondents' qualitative comments give insight into why they rated married couples as having a greater relationship satisfaction level than cohabitating couples. Several emerging adults in this sample thought that cohabitating relationships are unpredictable and that cohabiting partners feel insecure about their relationships. Many also expressed negative opinions about cohabitation and did not want this type of relationship for themselves in the long-term, especially if they had children. These findings suggest that emerging adults view marriage as more fulfilling than cohabitation without marriage. These findings also suggest that emerging adults place great importance on marriage, that marriage will likely continue to be the most valued achievement in adulthood, and that most individuals will remain committed and invested to the institution of marriage in their own lives.

\section{Perceptions of Satisfaction in Marital and Cohabiting Relationships with different Gender Roles}

Emerging adults perceived that satisfaction in various GRRs was not dependent on whether those couple relationships were married or cohabiting. The current study was the first to examine emerging adults' attitudes and beliefs about gender role relationships in cohabiting relationships. These findings 
suggest that the type of GRR the couple engages in does not influence the satisfaction level attributed to married or unmarried couples, and that regardless of marital status, couples are rated more positively when they are engaging in an egalitarian GRR than when they are engaging in a conventional or nonconventional relationship.

Perhaps emerging adults view both marriage and egalitarianism as contributing factors for a happy relationship, but do not view the presence of both as requirements. Based on this finding, it is assumed that most emerging adults will likely marry, and most will also desire and enter into an egalitarian gender role relationship, but many will not acquire both.

\section{Perceptions of Relationship Satisfaction in Child-Present and Child-Absent Relationships}

Emerging adults in the current study did not perceive that relationship satisfaction was dependent on the hypothetical couple's parental status. These findings suggest that couples with and without children are viewed similarly in regard to their relationship satisfaction and that, when projecting themselves into the relationship, emerging adults anticipate that their own relationship satisfaction would not differ with or without the presence of children. This was the first study that asked never-married, child-free emerging adults to hypothesize the satisfaction of child-absent and child-present couples and it advances our understanding of the way in which child-absent and child-present couples are viewed. Although previous research has shown that relationship satisfaction tends to decline with the presence of children (Cox et al., 1999; Crohan, 1996; Gable et al., 1995; Hackel \& Ruble, 1992; Lawrence et al., 2007; Lawrence et al., 2008; Umberson et al., 2005; Van Laningham et al., 2001; Waite \& Lillard, 1991; Wallace \& Gotlib, 1990), results from this study suggest that from an outsider's view, relationship satisfaction remains consistent with or without children present. Respondent's qualitative comments did not share much light on the quantitative results; less than $10 \%$ of respondents commented on children, and responses did not consistently indicate that respondents thought that children would increase or decrease relationship 
satisfaction. Perhaps these unmarried, childfree emerging adults are not yet thinking about how children may affect their future relationship dynamics.

These findings suggest that there have been recent changes in the way in which emerging adults think about families. This new line of thinking, which attributes equal fulfillment to both parenthood and nonparenthood, is also documented by Thornton and Young-DeMarco (2001), who found that in recent decades less men and women believe that "people who have never had children lead empty lives" and that "all married couples who can ought to have children" than ever before. It seems as though emerging adults do not view parenthood as a requirement for life satisfaction, and that they are granting themselves and others more tolerance and freedom to choose nonnormative family lifestyles. With this new tolerance of child-absent couples, there may be a decreased number of people having children in the future.

\section{Perceptions of Satisfaction in Child-Present and Child-Absent Relationships with different Gender}

\section{Roles}

Emerging adults perceived that satisfaction in various GRRs was not dependent on whether or not those couples had children. The current study was the first to examine emerging adults' attitudes and beliefs about GRRs across child-present and child-absent relationships. These findings suggest that the type of GRR the couple engages in does not influence the satisfaction level attributed to child-present or child-absent couples, and that regardless of parental status, couples are rated more positively when they are engaging in an egalitarian GRR than when they are engaging in a conventional or nonconventional relationship. The qualitative responses echo the lack of a GRR by parental status interaction effect in that few respondents mentioned that the presence (or absence) of children swayed their view of relationship satisfaction. 
Perhaps egalitarianism is viewed as the primary contributing factor for a happy relationship by emerging adults, while parenthood is not. Based on this finding, it is assumed that most emerging adults will desire and enter into an egalitarian GRR, with or without the presence of children.

\section{Strengths}

There are several noteworthy strengths to the current study's methodological design. First, this study went beyond previously published research to include five typologies of gender role relationships. Inclusion of five relationship types allowed for the examination of the continuum of gender role relationships. Not only were conventional types included (i.e., male-head/female-complement and malesenior/female-junior), but egalitarian and nonconventional types were also included (i.e., femalehead/male-complement and female-senior/male-junior).

Second, this study included three independent variables, something that had never been done previously in this topic area. Although GRRs have previously been examined in relation to perceived relationship satisfaction, the inclusion of marital status and parental status as independent variables is groundbreaking in this research area. The addition of marital status and parental status allowed for the examination of main effects and interaction effects.

Third, in order to examine variability in the way that respondents think about others' satisfaction with a given situation and their own satisfaction with the same situation, two dependent variables were used to assess respondent's views about relationship satisfaction. One measure was a general assessment of how respondents viewed the vignette couple's satisfaction, while the other measure was a personal assessment of how respondents anticipated their own satisfaction if they were in the scenario. No other study has used both a general and a personal measurement in this way.

Fourth, this study examined potential moderating variables between type of gender role relationship and views about relationship satisfaction. Although certain variables have been examined in 
relation to gender role ideology, they have never before been used to explain the relationship between gender role relationship and anticipated satisfaction level of that relationship.

Fifth, vignettes were used as a method of data collection. Vignettes are useful in social research because respondents often react to the characters' behaviors with strong emotions (Ganong \& Coleman, 2006), but also give less guarded responses (Finch, 1987) than when presented with other data collection methods. The qualitative findings of the study also make it possible to appraise the study's use of vignettes as a method of data collection. A small minority of respondents qualitatively cited that the vignette did not provide enough information for them to assess the couple's relationship satisfaction. These types of responses were also generally similar across GRR, marital status, and parental status assignments. This consistency indicates that most respondents were apparently able to form judgments about the couple based on the brief vignette paragraphs provided, and that none of the individual couple types demanded more information in order for participants to respond to the scales. Further, the majority of respondents cited relating the vignette couple's characteristics to their personal life or personal desires. Two conclusions are drawn from this: 1) Even when reporting on a hypothetical couple, it is difficult to form an objective opinion regarding relationship satisfaction and 2) Through identifying and personalizing with the information in the vignettes, respondents project themselves into the situation. Knowing that respondents generally thought that the vignette supplied them with enough information to form a judgment on the couple's satisfaction level and that they personalized with the vignette confirms the study's validity.

Sixth, this study employed both quantitative and qualitative methods and analyses. Not only were respondents asked to report on forced-answer questions, but they were also asked to explain their decisionmaking process via open-ended questions. Using a mixed method approach helped shed some light on what, why, and how emerging adults think about the satisfaction among partners in different types of GRRs. No other researchers in this topic area have employed a mixed method study in this manner. 
Seventh, because the sample typifies the next generation to put gender role relationships into practice, findings from the current study help us to understand trends in relationships. The beliefs of never-married, child-free, emerging adults are representations of what is acceptable in terms of GRRs, as well as what GRRs are likely to be practiced in the near future.

\section{Limitations}

Despite many strengths, the current study design also has a few limitations. First, the majority of the respondents who took part in this study were female and generally more educated than most other emerging adults. This lack of representativeness among genders and educational backgrounds is not surprisingly, as studies have found that women (Dunn, Jordan, Lacey, Shapley, \& Jinks, 2004; Eagan, Eide, Gulsvik, \& Bakke, 2002) and more educated persons (Partin et al., 2003) are more likely to participate in studies than men and less educated persons. However, the overrepresentation of these groups may reduce the generalizability of the study's findings to men and those with lower education levels. It should be noted, however, that the use of several recruitment strategies allowed for emerging adults across the country to participate in the study; setting the study apart from most in this topic area, the sample was not limited to one single geographical location.

Second, although the current study helps us understand how never-married, child-free, emerging adults presently think about the satisfaction among partners in different GRRs, as well as allows us to predict the types of GRRs they are likely to seek out in the future, it does not tell us in certainty the types of relationships emerging adults will choose. Only longitudinal studies are able to make these linkages.

Third, the two relationship satisfaction measures were couple-level variables, not individual-level variables. It may have been difficult for respondents to think about how satisfied the couple, as a whole, would be in certain situations; it may be easier to tease apart the satisfaction level of each partner and 
report on the male and female character separately. Autonomy, power, respect, and esteem all stem from paid work and employment (Scanzoni et al., 1989), so respondents may have had a particularly hard time rating the relationship satisfaction of couples engaging in the head/complement GRRs because one partner may be more satisfied with the arrangement than the other.

Fourth, the way respondent income was operationalized may have caused some confusion among respondents. They were asked to report on their total annual family income, which was intended to capture their family of origin's annual income level. While some respondents may have reported their family of origin's annual family income (i.e., their parent's as well as their own), others may have interpreted the question as only asking for their own annual income (i.e., without considering their parent's income). Income level was significantly and negatively related to respondent's age and education level, so it can be presumed that younger emerging adults and those with less education were more likely to report their family of origin's annual family income and older emerging adults and those with more education were more likely to report only their own income.

\section{Implications for Research}

The current study is groundbreaking in many aspects, which opens the door to new possibilities in research. Future research would benefit from using similar methods as employed in the current study. For instance, future research should delve deeper into the five GRR typologies established in this study. Also, the current study examined many possible moderators to the relationship between GRR and views about satisfaction. However, emerging adults' impressions of couple satisfaction may have been partly shaped by other life experiences not captured in the current study. Future studies should explore additional family variables (e.g., parental gender role attitudes, parental employment status, parental education level, sibling marital status) as well as individual variables (e.g., relationship experience, experience with children). As stated earlier, socialization theories (Bandura, 1977), as well as published research (Cunningham, 2001; 
Davis \& Wills, 2011; Marks et al., 2009), suggest that experiences in childhood and young adulthood help shape the characteristics that one considers ideal in a potential partner as well as one's attitudes toward marriage roles.

Perceived relationship satisfaction was used as an all-encompassing dependent variable in the current study, but it may be a product of many different beliefs about the couple. For instance, emerging adults may have attributed the partner-equal dyad as more stable, fair, successful, or functional and therefore expected it to be more satisfying. In fact, the respondent's qualitative responses confirm these assumptions. Also, the results of Cobb et al. (2003) suggest that egalitarian relationships are viewed as the most stable type of GRR, and egalitarian and nonconventional relationships are viewed as the most fair and satisfying. Future research should take into account these additional variables when measuring perceived satisfaction. Future research would also benefit from asking about the male's satisfaction and the female's satisfaction as two separate constructs.

Vignettes are not only highly validated methods of data collection (Ludwick \& Zeller, 2001), because they are capable of standardizing the situation depicted in the scenario and the possible responses to the scenario by controlling several dimensions (i.e., independent variables) and dependent variables (Gould, 1996; Rossi \& Berk, 1997), but they relay information to respondents in a quick fashion as well. Multiple vignettes can also be used in combination to change the context of the scenario. Using multipleevent vignettes allows the researcher to manipulate additional variables (e.g., loss of a job, disability that hinders a partner from working) within the same scenario and ask respondents to explain their attitudes after reading about each of the vignettes. Researchers should take notice of the benefits of using vignettes and implement them in their studies of social phenomena.

Using a mixed-methods approach (i.e., combining quantitative and qualitative approaches) to data collection and analysis, like employed in the current study, captures complexity and provides an in-depth 
understanding of phenomena (Klassen, 2012). Researchers studying areas in which using a quantitative or qualitative approach independently would not adequately formulate a complete understanding should consider using a mixed-method approach.

Along with face-to-face recruitment, the current study utilized several technological recruitment strategies to obtain a relatively diverse sample. By using technology as a launching point, a large sample that fit the inclusion criteria was able to be obtained. The advancements of Facebook and other listserves not only provide researchers with a safe, time-efficient way of distributing study information, but they also support the inclusion of both academic and non-academic respondents. Researchers are encouraged to draw on the web as a recruitment and data collection tool.

Emerging adults' perceived satisfaction with different types of GRRs are products of changing social norms, values, and practices, so it is important to examine how views about satisfaction may shift over time. The current study was able to elicit what emerging adults perceive as the ideal GRR, or what they deem as a standard GRR, but we are left wondering what GRRs they will practice in their future relationships and how they will relate to their ideal. Future research should longitudinally track emerging adults through their premarital years into their marital years so we can better understand what influences individuals to make gender role choices in their personal lives and how these choices change from one generation to the next.

\section{Implications for Practice}

The current study also lends itself to many practical implications. Over the past couple of decades, there has been a rise in the number of women shifting their focus from being solely responsible for the domestic tasks to working outside of the home, alongside men, in paid employment. With these changes, it has proven to be difficult for men and women to develop new gender roles regarding household and childrearing responsibilities to better adapt to their changing lifestyles (Gillis, 1995). Based on the 
findings of this study, the dual-career, egalitarian family in which both partners work outside of the home, and equally care for children and contribute to housework is thought to be the most satisfying type of family.

It is important for professionals in the social practice to know this information because the egalitarian family type will likely be the most sought-after type of GRR in the future generations. For example, family-life educators, pre-marital counselors, and marital counselors are responsible for working with and helping individuals and couples prepare for their future relationships, as well as maintain and/or mend their current relationships. Understanding the general perception of gender role relationships, and how it relates to age, gender, education level, income level, and other characteristics, will help practitioners identify their client's gender role preferences and provide appropriate counseling.

Although most studies suggest that emerging adults generally prefer egalitarian relationships, counselors may find that certain groups of people prefer other gender role relationships. Using the results from this study as an example, those with less education may find a conventional type of GRR as the most satisfying, whereas those who are less religious and those with less income may find a nonconventional type of GRR as the most satisfying. Counselors should recognize these idiosyncrasies and tailor their sessions around individual differences. For example, a couple may present themselves for pre-marital counseling and one partner in the couple may be more educated and less religious than the other. In this case, the counselor should understand that one partner may prefer to engage in a conventional GRR while the other may prefer a nonconventional GRR, and open discussion based on this possible point of conflict. Focusing on underlying beliefs of gender roles, power and control, and socialization, as well as flexibility in thought processes may help foster a better functioning relationship.

Recent trends in gender role expectations and beliefs bring to light trends in marriage and parenthood desires. Although marriage still seems to be valued and preferred by todays emerging adults, 
data from this study suggest that parenthood may have lost value to this group in recent decades. Married couples are perceived to be more satisfied than cohabitating, unmarried couples, but the presence of children does not seem to play a role in determining relationship satisfaction. This shows a trend of more tolerant views of what it means to be a happy, fulfilled family. Practitioners should be advised that not all individuals entering into marriage desire to have children, and that sometimes couples have not negotiated their parenthood desires prior to entering the relationship. It could be that each partner assumes that the other mirrors their desire for a child-absent or child-present relationship, and, thus, when the issue is finally discussed conflict arises.

Findings from this study also present practical implications by way of family-friendly workplace policies. For years, work-family policies have been designed around a male-head/female-complement gender role relationship. These "male breadwinner" policies may produce work-family conflict, as well as have negative effects on children because they have insufficient time with their parents. Although some egalitarian-friendly policies, such as parental leave policies, have been passed and are in place, many individuals do not know about the work-family programs available to them. Additionally, only fulltime working individuals are typically eligible to use such policies, and many employers shun the use of them even by eligible employees (Wallen, 2002). It is recommended that policy-makers tailor outdated policies to better support new trends in gender role relationships. Specifically, they should take note that most individuals prefer a dual-earner, egalitarian relationship, and that unlike in the past many families do not have a stay-at-home mother or father. Particularly in these cases, workplaces should allow more paid vacation and sick days, as well as adjusted work hours and paternity leave, to allow workers to spend more time at home with their families and/or sick children. Specifically, because schools are not scheduled around nine-to-five jobs, employers should be sympathetic to revise work schedules that correspond to the school districts hours. 
We will likely see men and women experience conflict as they adjust to new gender roles for years to come as policies and practices work to catch up with the ever-changing dynamics of families. Couples will, however, find a work-life balance if they are presented with the appropriate resources. 


\section{REFERENCES}

Amato, P. R., \& Booth, A. (1995). Changes in gender role attitudes and perceived marital quality. American Sociological Review, 60, 58-66.

Arnett, J. J. (2004). Emerging adulthood: The winding road from late teens through the twenties. Oxford: Oxford University Press.

Bandura, A. (1977). Social learning theory. Englewood Cliffs, NJ: Prentice-Hall.

Bang, E., Hall, M. E. L., Anderson, T. L., \& Willingham, M. M. (2005). Ethnicity, acculturation, and religiosity as predictors of female college students' role expectations. Sex Roles, 53, 231-237.

Barter, C., \& Renold, E. (1999). The use of vignettes in qualitative research. Social Research Update, 25, $1-4$.

Blakemore, J. E. O., Lawton, C. A., \& Vartanian, L. R. (2005). I can’t wait to get married: Gender differences in drive to marry. Sex Roles, 53, 327-335.

Bolzendahl, C. I., \& Myers, D. J. (2004). Feminist attitudes and support for gender equality: Opinion change in women and men, 1974-1998. Social Forces, 83, 759-790.

Botkin, D. R., Weeks, M. O., \& Morris, J. E. (2000). Changing marriage role expectations: 1961-1996. Sex Roles, 42, 933-942.

Boushey, H. (2009). The new breadwinners. In H. Boushey \& A. O'Leary (Eds.), The Shriver report: A woman's nation changes everything (pp. 30-67). Washington DC: Center for American Progress.

Brewster, K. L., \& Padavic, I. (2000). Change in gender ideology, 1977-1996: The contributions of intracohort change and population turnover. Journal of Marriage and Family, 62, 477-487.

Brown, S. L. (2003). Relationship quality dynamics of cohabiting unions. Journal of Family Issues, 24, 583-601.

Brown, S. L. \& Booth, A. (1996). Cohabitation versus marriage: A comparison of relationship quality. Journal of Marriage and the Family, 58, 668-678.

Brown, S. L. \& Kawamura, S. (2010). Relationship quality among cohabitors and married in older adulthood. Social Science Research, 39, 777-786.

Bryant, A. N. (2003). Changes in attitudes toward women's role: predicting gender-role traditionalism among college students. Sex Roles, 48, 131-142.

Budd, R. (1967). Content Analysis of Communications. New York: Macmillan Company. 
Cabrera, N. J., Tamis-LeMonda, C. S., Bradley, R. H., Hofferth, S., \& Lamb, M. E. (2000). Fatherhood in the twenty-first century. Child Development, 71, 127-136.

Carter, J. S., Corra, M., \& Carter, S. K. (2009). The interaction of race and gender: Changing gender-role attitudes, 1974-2006. Social Science Quarterly, 90, 196-211.

Cassidy, M. L., \& Warren, B. O. (1996). Family employment status and gender role attitudes, a comparison of women and men college graduates. Gender \& Society, 10, 312-329.

Cichy, K. E., Lefkowitz, E. S., \& Fingerman, K. L. (2007). Generational differences in gender attitudes between parents and grown offspring. Sex Roles, 57, 825-836.

Cobb, L. A., Seery, B. L., \& McKinney, K. (2003). College students' perceptions of employment-based marital dyad types. Journal of Family and Economic Issues, 24, 203-224.

Coleman, M., \& Ganong, L. H. (1984). Effect of family structure on family attitudes and expectations. Family Relations, 33, 425-432.

Cunningham, M. (2001). The influence of parental attitudes and behaviors on children's attitudes toward gender and household labor in early adulthood. Journal of Marriage and the Family, 63, 111-122.

Cunningham, M., Beutel, A., Barber, J. S., \& Thornton, A. (2005). Reciprocal relationships between attitudes about gender and social contexts during young adulthood. Social Science Research, 34, 862-892.

Davey, F.H. (1998). Young Women's Expected and Preferred Patterns of Employment and Child Care. Sex Roles, 38, 95-102.

Davis, N. J., \& Robinson, R. V. (1991). Men's and women's consciousness of gender inequality: Austria, West Germany, Great Britain, and the United States. American Sociological Review, 56, 72-84.

Davis, S. N., \& Wills, J. B. (2011). Adolescent gender socialization: Direct and moderating effects of fathers' beliefs. Sociological Spectrum, 30, 580-604.

Dillaway, H., \& Broman, C. (2001). Race, class, and gender differences in marital satisfaction and divisions of household labor among dual-earner couples: A case for intersectional analysis. Journal of Family Issues, 22, 309-327.

Dunn, K. M., Jordan, K., Lacey, R. J., Shapley, M., \& Jinks, C. (2004). Patterns of consent in epidemiologic research: Evidence from over 25,000 responders. American Journal of Epidemology, 159, 1087-1094.

Eagan, T. M., Eide, G. E., Gulsvik, A., \& Bakke, P. S. (2002). Nonresponse in a community cohort study: Predictors and consequences for exposure-disease associations. Journal of Clinical Epidemiology, $55,775-781$.

Fan, P., \& Marini, M. M. (2000). Influences on gender-role attitudes during the transition to adulthood. Social Science Research, 29, 258-283. 
Finch, J. (1987). Research note: The vignette technique in survey research. Sociology, 21, $105-114$.

Flaskerud, J. H. (1979). Use of vignettes to elicit responses toward broad concepts. Nursing Research, 28, 210-212.

Friedman, S. R., \& Weissbrod, C. S. (2005). Work and family commitment and decision-making status among emerging adults. Sex Roles, 53, 317-325.

Ganong, L., \& Coleman, M. (1992). Gender differences in self and future partner expectations. Journal of Family Issues, 13, 55-64.

Ganong, L., Coleman, M., Thompson, A., \& Goodwin-Watson, C. (1996). African American and European American college students' expectations for self and future partners. Journal of Family Issues, 17, 758-775.

Ganong, L. H., \& Coleman, M. (2006). Multiple segment factorial vignette designs. Journal of Marriage and Family, 68, 455-468.

Gillis, J. (1995). Bringing up father: British paternal identities, 1700 to present. Masculinities, 3, 1-27.

Gould, D. (1996). Using vignettes to collect data for nursing research studies: how valid are the findings? Journal of Clinical Nursing, 5, 207-212.

Greene, A. L., \& Wheatley, S. M. (1992). "I've got a lot to do and I don't think I'll have the time": Gender differences in late adolescents' narratives of the future. Journal of Youth and Adolescence, 21, $667-686$.

Hartung, P. J., \& Rogers, J. R. (2000). Work-family commitment and attitudes toward feminism in medical students. Career Development Quarterly, 48, 264-275.

Helms, H. M., Walls, J. K., Crouter, A. C., \& McHale, S. M. (2010). Provider role attitudes, marital satisfaction, role overload, and housework: A dyadic approach. Journal of Family Psychology, 24, 568-577.

Helms-Erikson, H., Tanner, J. L., Crouter, A. C., \& McHale, S. M. (2000). Do women's provider-role attitudes moderate the links between work and family? Journal of Family Psychology, 14, 658670.

Heuveline, P., \& Timberlake, J. M. (2004). The role of cohabitation in family formation: The United States in comparative perspective. Journal of Marriage and the Family, 66, 1214-1230.

Hoffnung, M. (2004). Wanting it all: Career, marriage, and motherhood during college-educated women's 20s. Sex Roles, 50, 711-723.

Hughes, R., \& Huby, M. (2002). The application of vignettes in social and nursing research. Journal of Advanced Nursing, 37, 382-386. 
Huston, T. L., McHale, S. M., \& Crouter, A. C. (1986). When the honeymoon's over: Changes in the marriage relationship over the first year. In R. Gilmore \& S. Duck (Eds.), The emerging field of personal relationships (pp. 109-132). Hillsdale, NJ: Erlbaum.

Kaufman, G. (2005) Gender role attitudes and college students' work and family expectations. Gender Issues, 22, 58-71.

Kerpelman, J. L., \& Schvaneveldt, P. L. (1999). Young adults' anticipated identity importance of career, marital, and parental roles: Comparisons of men and women with different role balance orientations. Sex Roles, 41, 189-217.

Kirkpatrick, L. A., Hood, R. W., Jr., \& Hartz, G. (1991). Fundamentalist religion conceptualized in terms of Rokeach's theory of the open and closed mind: New perspectives on some old ideas. In M. L. Lynn \& D. O. Moberg (Eds.), Research in the social scientific study of religion: A research annual (Vol. 3, pp. 157-180). Greenwich, CT: JAI Press.

Klassen, A. C., Creswell, J., Plano Clark, V. L., Clegg Smith, K., \& Meissner, H. I. (2012). Best practices in mixed methods for quality of life research. Quality of Life Research, 21, 377-380.

Kroska, A. (2000). Conceptualizing and measuring gender ideology as an identity. Gender \& Society, 14, 368-394.

Kulik, L. (2002). The impact of social background on gender-role ideology: Parents' versus children's attitudes. Journal of Family Issues, 23, 53-73.

Leech, T. G. J. (2010). Everything's better in moderation: Young women's gender role attitudes and risky sexual behavior. Journal of Adolescent Health, 46, 437-443.

Livingston, M. M., Burley, K., \& Springer, T. P. (1996). The importance of being feminine: Gender, sex role, occupational and marital role commitment, and their relationship to anticipated work-family conflict. Journal of Social Behavior and Personality, 11, 179-192.

Ludwick, R., Wright, M. E., Zeller, R. A., Dowding, D. W., Lauder, W., \& Winchell, J. (2004). An improved methodology for advancing nursing research: Factorial surveys. Advances in Nursing Science, 27, $224-238$.

Ludwick, R., \& Zeller, R. A. (2001). The factorial survey: An experimental method to replicate real world problems. Nursing Research, 50, $129-133$.

Machung, A. (1989). Talking Career, Thinking Jobs: Gender Differences in Career and Family Expectations of Berkeley Seniors. Feminist Studies, 15, 35-58.

Marks, J. L., Lam, C. B., \& McHale, S. M. (2009). Family patterns of gender role attitudes. Sex Roles, 61, 221-234.

Mickelson, K. D., Claffey, S. T., Williams, S. L. (2006). The moderating role of gender and gender role attitudes on the link between spousal support and marital quality. Sex Roles, 55, 73-82. 
Moen, P., Erickson, M. A., \& Dempster-McClain, D. (1997). Their mother's daughters? The intergenerational transmission of gender attitudes in a world of changing roles. Journal of Marriage and Family, 59, 281-293.

Morgan, C.S., \& Affleck, M. (1989). College Women's Expectations for Work and Family. Free Inquiry in Creative Sociology, 17, 207-212.

Myers, S. M., \& Booth, A. (2002). Forerunners of change in nontraditional gender ideology. Social Psychology Quarterly, 65, 18-37.

Niles, S. G., \& Goodnough, G. E. (1996). Life-role salience and values: A review of recent research. Career Development Quarterly, 45, 65-86.

Nock, S. L. (1995). A comparison of marriage and cohabiting relationships. Journal of Family Issues, 16, 53-76.

Novack, L. L., \& Novack, D. R. (1996). Being female in the eighties and nineties: Conflicts between new opportunities and traditional expectations among White, middle class, heterosexual college women. Sex Roles, 35, 57-77.

Partin, M. R., Malone, M., Winnett, M., Slater, J., Bar-Cohen, A., \& Caplan, L. (2003). The impact of survey nonresponse bias on conclusions drawn from a mammography intervention trial. Journal of Clinical Epidemiology, 56, 867-873.

Pearce, L. D., Thornton, A. (2007). Religious identity and family ideologies in the transition to adulthood. Journal of Marriage and Family, 69, 1227-1243.

Pedersen, D. E. (2010). Measuring "gender ideological identity": Vignettes for young men and women. The Social Science Journal, 47, 447-459.

Peek, C. W., Lowe, G. D., \& Williams, L. S. (1991). Gender and God's word: Another look at religious fundamentalism and sexism. Social Forces, 69, 1205-1221.

Perry-Jenkins, M., \& Folk, K. (1994). Class, couples, and conflict: Effects of the division of labor on assessments of marriage in dual-earner families. Journal of Marriage and Family, 56, 165-180.

Pleck, J. H. (2010). Paternal involvement: Revised conceptualization and theoretical linkages with child outcomes. In M. E. Lamb (Ed.), The role of the father in child development (5th ed., pp. 58-93). Hoboken, NJ: Wiley.

Powers, R. S., Suiter, J. J., Guerra, S., Shackelford, M., Mecom, D., \& Gusman, K. (2003). Regional differences in gender-role attitudes: Variations by gender and race. Gender Issues, 21, 40-54.

Rhodebeck, L. A. (1996). The structure of men's and women's feminist orientations, feminist identity and feminist opinion. Gender \& Society, 10, 386-403.

Rogers, S. J., \& Amato, P. R. (1997). Is marital quality declining? The evidence from two generations. Social Forces, 75, 1089-1100. 
Rossi, P., \& Berk, R. (1997). Just punishments. New York: deGruyter.

Rossi, P., \& Nock, S. (1982). (Eds.). Measuring social judgments. Beverly Hills, CA: Sage.

Rossi, A., \& Rossi, P. (1990). Of human bonding. New York: Aldine deGruyter.

Scanzoni, J. (1995). Contemporary families and relationships: Reinventing responsibility. New York: McGraw-Hill.

Scanzoni, J., Polonko, K., Teachman, J., \& Thompson, L. (1989). The sexual bond: Rethinking families and close relationships. Newbury Park, CA: Sage.

Scanzoni, L. D., \& Scanzoni, J. (1988). Men, women, and change: A sociology of marriage and family ( ${ }^{\text {rd }}$ ed.). New York: McGraw-Hill.

Schroeder, K. A., Blood, L. L., \& Maluso, D. (1992). An Intergenerational Analysis of Expectations for Women's Career and Family Roles. Sex Roles, 26, 273-91.

Schroeder, K. A., Blood, L. L., \& Maluso, D. (1993). Gender differences and similarities between male and female undergraduate students regarding expectations for career and family roles. College Student Journal, 27, 237-249.

Spade, J. Z., \& Reese, C. A. (1991). We've come a long way, maybe: College students' plans for work and family. Sex Roles, 24, 309-321.

Sutton, S. (1998). Predicting and explaining intentions and behavior: How well are we doing? Journal of Applied Social Psychology, 28, 1317-1338.

Tallichet, S. E., \& Willits. F. K. (1986). Gender-role attitude change of young women: Influential factors from a panel study. Social Psychology Quarterly, 49, 219-227.

Thornton, A., Alwin, D. F., \& Camburn, D. (1983). Causes and consequences of sex-role attitudes and attitude change. American Sociological Review, 48, 211-227.

Thornton, A., \& Young-DeMarco, L. (2001). Four decades of trends in attitudes toward family issues in the United States: The 1960s through the 1990s. Journal of Marriage and Family, 63, 1009-1037.

U.S. Census Bureau, Current Population Survey, 2011 Annual Social and Economic Supplement. (2011). Table 1. Educational attainment of the population 18 years and over, by age, sex, race, and Hispanic origin: 2011. Retrieved from http://www.census.gov/hhes/socdemo/education/data/cps/ 2011/tables.html.

U.S. Census Bureau, Current Population Survey, 2008 Annual Social and Economic Supplement. (2008). Table FG8. Married couple family groups with children under 15 by stay-at-home status of both spouses: 2008. Retrieved from http://www.census.gov/population/www/socdemo/hhfam/cps2008.html. 
U.S. Census Bureau, Current Population Survey, 2011 Annual Social and Economic Supplement. (2011). Table FG8. Married couple family groups with children under 15 by stay-at-home status of both spouses: 2011 . Retrieved from http://www.census.gov/population/www/socdemo/hhfam/cps2011.html.

U.S. Census Bureau, Current Population Survey, Labor Force Statistics. (2011). Household data annual averages: Employment status of the civilian noninstitutional population by age, sex and race. Retrieved from http://www.bls.gov/cps/cpsaat03.html.

Wallen, J. (2002). Work and family programs and economic equality. In Balancing Work and Family: The Role of the Workplace (pp.119-129). Boston, MA: Allyn \& Bacon.

Wilkie, J. R., Ferree, M. M., \& Ratcliff, K. S. (1998). Gender and Fairness: Marital satisfaction in twoearner couples. Journal of Marriage and Family, 60, 577-594.

Willetts, M.C. (2006). Union quality comparisons between long-term heterosexual cohabitation and legal marriage. Journal of Family Issues, 27, 110-127.

Zuo, J., \& Tang, S. (2000). Breadwinner status and gender ideologies of men and women regarding family roles. Sociological Perspectives, 43, 29-43. 
APPENDIX A: RECRUITMENT FLYER 


\section{Attention: \\ Adults between 18 and 29 \\ You are invited to participate in a study on gender role preferences.}

My name is Tamara Coon Sells and I am a doctoral student studying at the University of Missouri. I am recruiting participants for my dissertation research, which will examine relationship perceptions.

If you are between the ages of 18 and 29, have never been married, and do not have children, I am interested in your participation in this study.

Participation entails completing a short, confidential online questionnaire that will take you between five and ten minutes to complete. No names will be used, so you will remain anonymous. You may find that participating in the survey helps you think about romantic relationships. Educators and marriage counselors may be able to use this information to help emerging adults prepare for their future gender roles.

If you are interested in participating, please go to this link (www.surveymonkey.com/s/gender_roles) and follow the instructions. I hope that you will consider participating in this research. Thank you in advance for your time and consideration and for allowing me the opportunity to tell you more about my research.

Please contact me if you have any questions about this research. Thank you, Tamara Coon Sells, M.S. 
Phone: 573-473-7771

Email: tgc8qd@mail.missouri.edu 
APPENDIX B: INFORMED CONSENT/COVERLETTER 
Researcher: Tamara Coon Sells is a graduate student in the Department of Human Development and Family Studies at the University of Missouri-Columbia.

Purpose: The purpose of this study is to examine perceptions about romantic relationships.

Time: $\quad$ Participation entails completing a short, anonymous, and confidential online questionnaire. In total, time of participation will be between five and ten minutes.

Voluntary: Your participation is voluntary. You have the right to refuse consent, choose to skip a question, or stop the survey process early if you choose.

Risk: $\quad$ The probability and magnitude of harm or discomfort anticipated in the research are not greater in and of themselves than those encountered in daily life. Although unexpected, if you experience discomfort while answering questions about gender roles, you may find it helpful to contact a counselor. Therapists.psychologytoday.com and goodtherapy.org are useful tools for locating a therapist or counselor in your area.

Benefits: $\quad$ You may find that participating in the survey helps you think about romantic relationships. Educators, as well as pre-marital and marriage counselors, may be able to use this information to help emerging adults prepare for their future gender roles.

Confidential: To ensure anonymity and to protect your privacy, no identifying information will be collected as part of this research. Your identity will remain anonymous and confidential. Further, all electronic data will be password protected, and all other data will be kept in a locked filing cabinet, to which only I (i.e., the principal investigator) will have a key.

Contact: If you have questions, feel free to contact Tamara Coon Sells at (573) 473-7771. You may also email at tgc8qd@mail.missouri.edu

Questions: If you have questions about your rights as an informant for this study, you may contact University of Missouri Campus IRB:

Office of Research

483 McReynolds Hall

Columbia, MO 65211

(573) $882-9585$

\section{Clicking on the "Accept" icon below indicates that you understand and consent to the research described above.}


APPENDIX C: DEMOGRAPHIC QUESTIONNAIRE 
What is your current age in years?

How many children do you have?

What sexual orientation do you identify with?

Heterosexual
Gay/Lesbian
Bisexual

What is your gender?

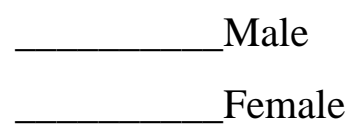

How many years of education have you had?

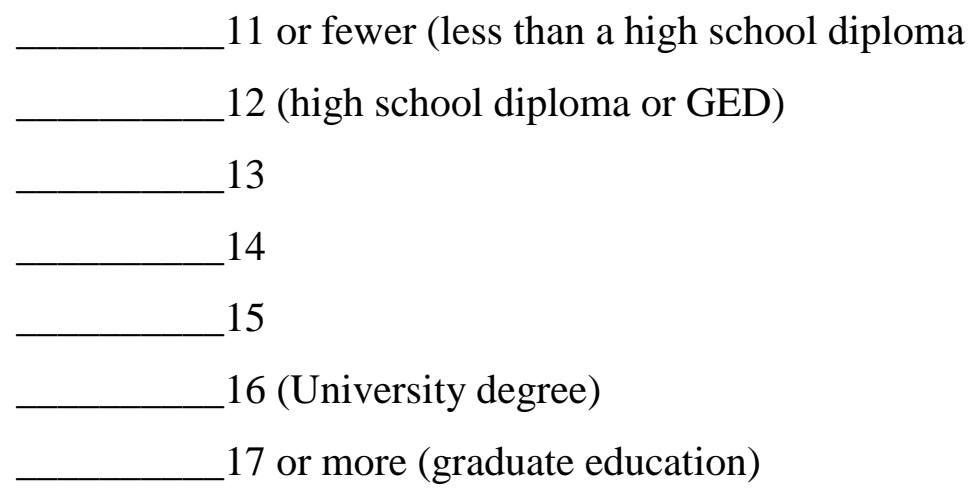

Which of the following best describes your racial identification?

White

Black or African American

Native American or Alaska Native

Asian

Native Hawaiian or Other Pacific Islander

Other (please specify): 
Which of the following ethnicities do you most closely identify with?

Hispanic or Latino

Non-Hispanic or non-Latino

Which of the following best describes your current relationship status?

Single, not dating

Single, dating casually

Dating one person exclusively, not living together

Dating one person exclusively, cohabitating

Engaged, not living together

Engaged, cohabitating

Married

Divorced

Which of the following religious groups do you most closely identify with?

Evangelical Protestant Churches (for example, Southern Baptist, Methodist,

Nondenominational evangelical, Lutheran Church, Presbyterian Church in America,

Pentecostal)

Historically Black Churches (for example, National Baptist Convention, African

Methodist Episcopal, Nondenominational, Church of God in Christ)

Mainline Protestant Churches (for example, American Baptist Churches, United

Methodist Church, Episcopal, ELCA, Presbyterian Church USA)

Catholic

Mormon

Jehovah's Witness

Orthodox (for example, Greek Orthodox, Russian Orthodox)

Other Christian (for example, metaphysical)

Jewish (for example, Reform, Conservative, Orthodox) 
Buddhist

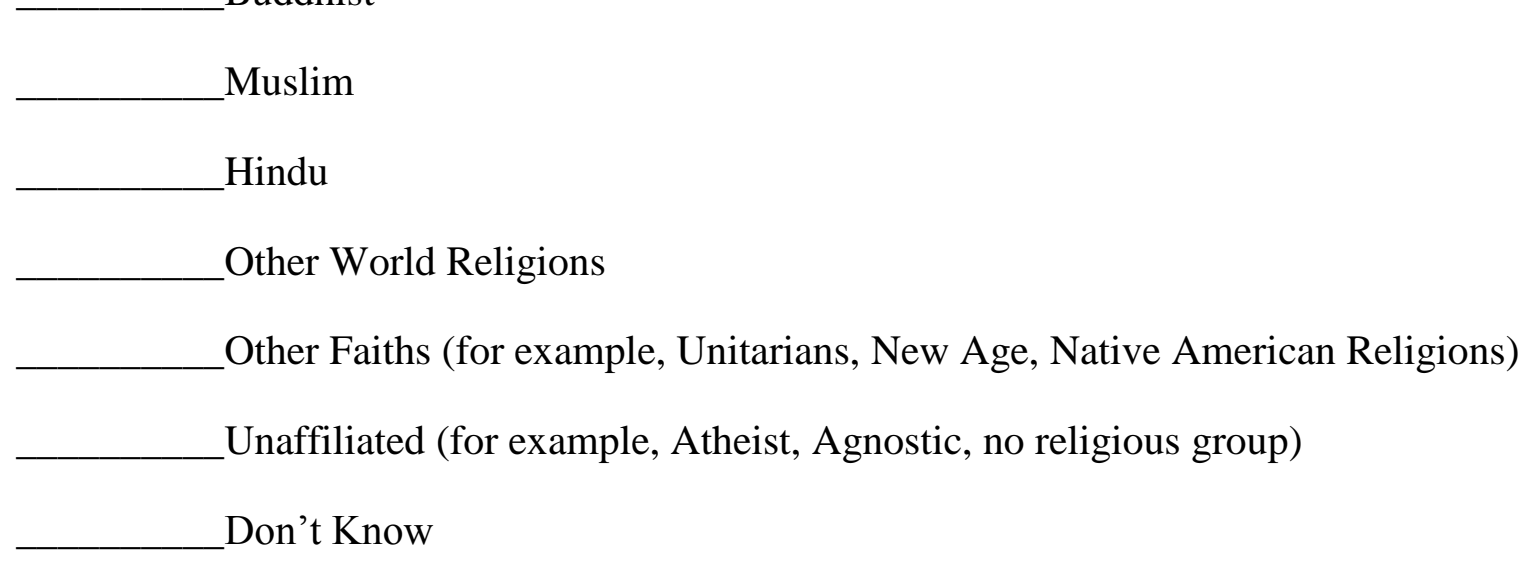

If you are unsure of which of these religious groups you identify with, please write in which church and/or religious affiliation, if any, you belong to.

Would you say you are:

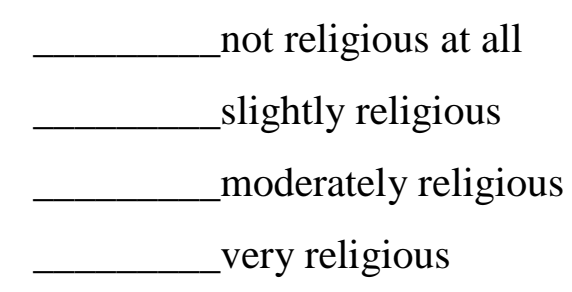

Which of the following were true of your family when you were a child (up to age 18) (check as many as apply):

$\ldots$ my parents were married
my parents divorced
my parents lived together but were never married
m_ my dad died
my mom died
my dad remarried
my mom remarried
I had biological brothers and/or sisters
I had stepbrothers and/or stepsisters


What is the highest education level attained by your father?

Less than a high school diploma

High school diploma or GED

Two-year college degree

Four-year college degree

Graduate degree

Which of the following best describes the employment status of your father for the majority of your childhood?

Did not work in paid employment

Worked part-time

Worked full-time

Which of the following best describes the employment status of your mother for the majority of your childhood?

Did not work in paid employment

Worked part-time

Worked full-time

What is the highest education level attained by your mother?

Less than a high school diploma

High school diploma or GED

Two-year college degree

Four-year college degree

Graduate degree

Which of the following categories best describes your total family income during the last year? less than $\$ 20,000$

$\$ 20,000-39,999$

$\$ 40,000-59,999$

$\$ 60,000-79,999$ 
$\$ 80,000-99,999$

$\$ 100,000-149,999$

$\$ 150,000-199,999$

$\$ 200,000$ or more 
APPENDIX D: VIGNETTES 


\section{Vignette 1}

\section{Married Couples without Children}

\section{Male-head/female-complement}

Joe and Courtney have been married for five years. They do not have children. Joe is a corporate executive and provides very well financially. He is also the family's primary decision-maker. Courtney does not work in paid employment and does not have an income. Instead, she assumes all of the household responsibilities.

\section{Male-senior/female-junior}

Joe and Courtney have been married for five years. They do not have children. Joe is a corporate executive and provides very well financially. He makes the majority of the family's decisions, although Courtney also helps make decisions for the family as well. Courtney is a part-time manager of a retail store. She assumes the majority of the household responsibilities, although Joe contributes a small amount to these tasks as well.

\section{Partner-equal}

Joe and Courtney have been married for five years. They do not have children. They are both corporate executives and provide very well financially. Joe and Courtney negotiate family decisions together. Joe and Courtney also share the household responsibilities equally.

\section{Female-senior/male-junior}

Courtney and Joe have been married for five years. They do not have children. Courtney is a corporate executive and provides very well financially. She makes the majority of the family's decisions, although Joe also helps make decisions for the family as well. Joe is a part-time manager of a retail store. He assumes the majority of the household responsibilities, although Courtney contributes a small amount to these tasks as well.

\section{Female-head/male-complement}

Courtney and Joe have been married for five years. They do not have children. Courtney is a corporate executive and provides very well financially. She is also the family's primary decision-maker. Joe does not work in paid employment and does not have an income. Instead, he assumes all of the household responsibilities. 


\section{Married Couples with Children}

\section{Male-head/female-complement}

Joe and Courtney have been married for five years and have two children together. Joe is a corporate executive and provides very well financially. He is also the family's primary decision-maker. Courtney does not work in paid employment and does not have an income. Instead, she assumes all of the household and child-rearing responsibilities.

\section{Male-senior/female-junior}

Joe and Courtney have been married for five years and have two children together. Joe is a corporate executive and provides very well financially. He makes the majority of the family's decisions, although Courtney also helps make decisions for the family as well. Courtney is a part-time manager of a retail store. She assumes the majority of the household and child-rearing responsibilities, although Joe contributes a small amount to these tasks as well.

\section{Partner-equal}

Joe and Courtney have been married for five years and have two children together. They are both corporate executives and provide very well financially. Joe and Courtney negotiate family decisions together. Joe and Courtney also share the household and child-rearing responsibilities equally.

\section{Female-senior/male-junior}

Courtney and Joe have been married for five years and have two children together. Courtney is a corporate executive and provides very well financially. She makes the majority of the family's decisions, although Joe also helps make decisions for the family as well. Joe is a part-time manager of a retail store. He assumes the majority of the household and child-rearing responsibilities, although Courtney contributes a small amount to these tasks as well.

\section{Female-head/male-complement}

Courtney and Joe have been married for five years and have two children together. Courtney is a corporate executive and provides very well financially. She is also the family's primary decision-maker. Joe does not work in paid employment and does not have an income. Instead, he assumes all of the household and child-rearing responsibilities. 


\section{Cohabitating Couples without Children}

\section{Male-head/female-complement}

Joe and Courtney have been living together for five years, but are not married. They do not have children. Joe is a corporate executive and provides very well financially. He is also the family's primary decisionmaker. Courtney does not work in paid employment and does not have an income. Instead, she assumes all of the household responsibilities.

\section{Male-senior/female-junior}

Joe and Courtney have been living together for five years, but are not married. They do not have children. Joe is a corporate executive and provides very well financially. He makes the majority of the family's decisions, although Courtney also helps make decisions for the family as well. Courtney is a part-time manager of a retail store. She assumes the majority of the household responsibilities, although Joe contributes a small amount to these tasks as well.

\section{Partner-equal}

Joe and Courtney have been living together for five years, but are not married. They do not have children. They are both corporate executives and provide very well financially. Joe and Courtney negotiate family decisions together. Joe and Courtney also share the household responsibilities equally.

\section{Female-senior/male-junior}

Courtney and Joe have been living together for five years, but are not married. They do not have children. Courtney is a corporate executive and provides very well financially. She makes the majority of the family's decisions, although Joe also helps make decisions for the family as well. Joe is a part-time manager of a retail store. He assumes the majority of the household responsibilities, although Courtney contributes a small amount to these tasks as well.

\section{Female-head/male-complement}

Courtney and Joe have been living together for five years, but are not married. They do not have children. Courtney is a corporate executive and provides very well financially. She is also the family's primary decision-maker. Joe does not work in paid employment and does not have an income. Instead, he assumes all of the household responsibilities. 


\section{Cohabiting Couples with Children}

\section{Male-head/female-complement}

Joe and Courtney have been living together for five years, but are not married. They have two children together. Joe is a corporate executive and provides very well financially. He is also the family's primary decision-maker. Courtney does not work in paid employment and does not have an income. Instead, she assumes all of the household and child-rearing responsibilities.

\section{Male-senior/female-junior}

Joe and Courtney have been living together for five years, but are not married. They have two children together. Joe is a corporate executive and provides very well financially. He makes the majority of the family's decisions, although Courtney also helps make decisions for the family as well. Courtney is a parttime manager of a retail store. She assumes the majority of the household and child-rearing responsibilities, although Joe contributes a small amount to these tasks as well.

\section{Partner-equal}

Joe and Courtney have been living together for five years, but are not married. They have two children together. They are both corporate executives and provide very well financially. Joe and Courtney negotiate family decisions together. Joe and Courtney also share the household and child-rearing responsibilities equally.

\section{Female-senior/male-junior}

Courtney and Joe have been living together for five years, but are not married. They have two children together. Courtney is a corporate executive and provides very well financially. She makes the majority of the family's decisions, although Joe also helps make decisions for the family as well. Joe is a part-time manager of a retail store. He assumes the majority of the household and child-rearing responsibilities, although Courtney contributes a small amount to these tasks as well.

\section{Female-head/male-complement}

Courtney and Joe have been living together for five years, but are not married. They have two children together. Courtney is a corporate executive and provides very well financially. She is also the family's primary decision-maker. Joe does not work in paid employment and does not have an income. Instead, he assumes all of the household and child-rearing responsibilities. 
APPENDIX E: PERCEIVED RELATIONSHIP SATISFACTION MEASURE 
There is a still a lot you don't know about Joe and Courtney, but based on what you know about them, I would like you to use the following words to describe how you feel about their relationship. For example, if you think Joe and Courtney's relationship is very "Bad", click on the number right next to the word "Bad". If you think it is very "Good", click on the number right next to the word "Good". If you think it is somewhere in between, click on the number that you think best describes the relationship.

$\mathrm{Bad}$

Good

1

$$
2
$$

3

4

5

6

7

Unsuccessful

1

2

3

4

5

Successful

Hard

$1+2$

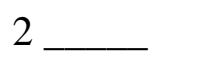

3

4

5

6

Easy

Friendly

1

2

3

4

5

6

Unfriendly

Fair

2

3

4

5

6

Unfair

1

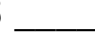

5

7 
Conflictual

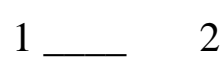

2

3

4

5

6

7

Worthwhile

1

2

3

3

4

4

Rigid

1

2

4

5

6

Flexible

7

Enjoyable

Miserable

1

2

3

4

5

6

7

Boring

Interesting

3

4

5

6

7

Disappointing

Rewarding

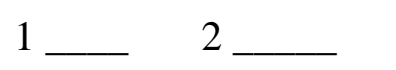

3

4

5

6

7

All things considered, how satisfying do you think this relationship is for the couple?

Very dissatisfying

Very satisfying 
Please explain why you rated the couples' satisfaction this way.

All things considered, how satisfying do you think this relationship would be for you?

Very dissatisfying

$1+2$ $3+\quad 4$
Very satisfying

5

6

7

Please explain why you rated your own satisfaction this way. 
Table 1

Frequency Distributions among Demographic Variables

\begin{tabular}{|c|c|c|c|}
\hline Variable & & $N$ & Percent \\
\hline \multirow[t]{12}{*}{ Age } & 18 & 54 & 12.0 \\
\hline & 19 & 68 & 15.1 \\
\hline & 20 & 57 & 12.6 \\
\hline & 21 & 70 & 15.5 \\
\hline & 22 & 45 & 10.0 \\
\hline & 23 & 33 & 7.3 \\
\hline & 24 & 28 & 6.2 \\
\hline & 25 & 27 & 6.0 \\
\hline & 26 & 18 & 4.0 \\
\hline & 27 & 13 & 2.9 \\
\hline & 28 & 22 & 4.9 \\
\hline & 29 & 16 & 3.5 \\
\hline \multirow[t]{2}{*}{ Gender } & Male & 62 & 13.7 \\
\hline & Female & 389 & 86.3 \\
\hline \multirow[t]{3}{*}{ Sexual Orientation } & Heterosexual & 425 & 94.4 \\
\hline & Gay/Lesbian & 10 & 2.2 \\
\hline & Bisexual & 15 & 3.3 \\
\hline \multirow[t]{6}{*}{ Education } & 12 (H.S. diploma or GED) & 40 & 8.9 \\
\hline & 13 & 71 & 15.7 \\
\hline & 14 & 63 & 14.0 \\
\hline & 15 & 82 & 18.2 \\
\hline & 16 (University degree) & 82 & 18.2 \\
\hline & 17 or more (Graduate education) & 113 & 25.1 \\
\hline \multirow[t]{4}{*}{ Religiosity } & Not religious at all & 90 & 20.0 \\
\hline & Slightly religious & 117 & 26.0 \\
\hline & Moderately religious & 162 & 36.0 \\
\hline & Very religious & 81 & 18.0 \\
\hline
\end{tabular}


Table 1 cont

Frequency Distributions among Demographic Variables

\begin{tabular}{|c|c|c|c|}
\hline Variable & & $N$ & Percent \\
\hline \multirow[t]{8}{*}{ Income } & less than $\$ 20,000$ & 29 & 6.7 \\
\hline & $\$ 20,000-39,999$ & 76 & 17.4 \\
\hline & $\$ 40,000$ - 59,999 & 69 & 15.8 \\
\hline & $\$ 60,000$ - 79,999 & 51 & 11.7 \\
\hline & $\$ 80,000-99,999$ & 48 & 11.0 \\
\hline & $\$ 100,000-149,999$ & 79 & 18.1 \\
\hline & $\$ 150,000$ - 199,999 & 36 & 8.3 \\
\hline & $\$ 200,000$ or more & 48 & 11.0 \\
\hline \multirow[t]{2}{*}{ Race } & White & 387 & 85.8 \\
\hline & Nonwhite & 64 & 14.2 \\
\hline \multirow[t]{2}{*}{ Ethnicity } & Hispanic or Latino & 23 & 5.1 \\
\hline & Non-Hispanic or Latino & 428 & 94.9 \\
\hline \multirow{2}{*}{$\begin{array}{l}\text { Parents' } \\
\text { marital status }\end{array}$} & Non-married & 121 & 26.8 \\
\hline & Married & 330 & 73.2 \\
\hline \multirow{3}{*}{$\begin{array}{l}\text { Father's } \\
\text { employment }\end{array}$} & Did not work in paid employment & 13 & 2.9 \\
\hline & Worked part-time & 9 & 2.0 \\
\hline & Worked full-time & 428 & 95.1 \\
\hline \multirow{3}{*}{$\begin{array}{l}\text { Mother's } \\
\text { employment }\end{array}$} & Did not work in paid employment & 98 & 21.8 \\
\hline & Worked part-time & 101 & 22.4 \\
\hline & Worked full-time & 251 & 55.8 \\
\hline \multirow{5}{*}{$\begin{array}{l}\text { Father's } \\
\text { education }\end{array}$} & Less than a H.S. diploma & 12 & 2.7 \\
\hline & H.S. diploma or GED & 126 & 27.9 \\
\hline & Two-year college degree & 38 & 8.4 \\
\hline & Four-year degree & 171 & 37.9 \\
\hline & Graduate degree & 104 & 23.1 \\
\hline \multirow{5}{*}{$\begin{array}{l}\text { Mother's } \\
\text { education }\end{array}$} & Less than a H.S. diploma & 10 & 2.2 \\
\hline & H.S. diploma or GED & 136 & 30.2 \\
\hline & Two-year degree & 62 & 13.8 \\
\hline & Four-year degree & 158 & 35.1 \\
\hline & Graduate degree & 84 & 18.7 \\
\hline
\end{tabular}


Table 2

Descriptive Statistics and Correlations among Study Variables $(N=422)$

\begin{tabular}{|c|c|c|c|c|c|c|c|c|}
\hline & 1. & 2. & 3. & 4. & 5. & 6. & 7. & 8. \\
\hline 1. Gender & - & & & & & & & \\
\hline 2. Education & -.06 & - & & & & & & \\
\hline 3. Religiosity & $-.18^{* *}$ & .04 & - & & & & & \\
\hline 4. Income & -.04 & $-.27^{* *}$ & -.06 & - & & & & \\
\hline 5. Parents' marital status & -.02 & -.03 & $-.12^{*}$ & $.30^{* *}$ & - & & & \\
\hline 6. $\mathrm{CSSD}^{\mathrm{a}}$ & -.05 & -.01 & $.12^{*}$ & .07 & -.01 & - & & \\
\hline 7. $\mathrm{APS}^{\mathrm{b}}$ & $-.12^{*}$ & .00 & $.24^{* *}$ & -.02 & -.02 & $.61^{* *}$ & - & \\
\hline 8. $\mathrm{GRR}^{\mathrm{c}}$ & - & - & - & - & - & .07 & -.01 & - \\
\hline$M(S D)$ & - & - & - & - & - & $4.57(.93)$ & $3.47(1.89)$ & - \\
\hline
\end{tabular}

$\underset{N}{N} * p<.05 . * * p<.01$.

a. CSSD = Couple Satisfaction Semantic Differential

b. APS = Anticipated Personal Satisfaction

c. GRR = Gender Role Relationship assignment 
Table 3

Means and Standard Deviations of CSSD and APS by GRR, Marital Status, and Parental Status

\begin{tabular}{|c|c|c|c|c|c|c|c|}
\hline \multirow[b]{2}{*}{$\mathrm{GRR}_{\mathrm{c}}$} & \multirow[b]{2}{*}{ Marital Status } & \multirow[b]{2}{*}{ Parental Status } & \multirow[b]{2}{*}{$N$} & \multicolumn{2}{|c|}{$\mathrm{CSSD}_{\mathrm{a}}$} & \multicolumn{2}{|c|}{$\mathrm{APS}_{\mathrm{b}}$} \\
\hline & & & & Mean & $\mathrm{SD}$ & Mean & $\mathrm{SD}$ \\
\hline \multirow[t]{9}{*}{ Mhead $_{d}$} & \multirow[t]{3}{*}{ Unmarried } & Child-absent & 21 & 4.06 & 0.52 & 2.19 & 1.36 \\
\hline & & Child-present & 21 & 4.34 & 0.95 & 3.19 & 2.02 \\
\hline & & Total & 42 & 4.20 & 0.77 & 2.69 & 1.77 \\
\hline & \multirow[t]{3}{*}{ Married } & Child-absent & 27 & 4.49 & 1.03 & 3.26 & 1.83 \\
\hline & & Child-present & 22 & 4.46 & 0.95 & 3.91 & 1.90 \\
\hline & & Total & 49 & 4.48 & 0.99 & 3.55 & 1.87 \\
\hline & \multirow[t]{3}{*}{ Total } & Child-absent & 48 & 4.30 & 0.87 & 2.79 & 1.71 \\
\hline & & Child-present & 43 & 4.40 & 0.94 & 3.56 & 1.97 \\
\hline & & Total & 91 & 4.35 & 0.90 & 3.15 & 1.87 \\
\hline \multirow[t]{9}{*}{ Msenior $_{\mathrm{e}}$} & \multirow[t]{3}{*}{ Unmarried } & Child-absent & 27 & 4.42 & 0.81 & 2.81 & 1.42 \\
\hline & & Child-present & 15 & 4.11 & 0.60 & 2.40 & 1.40 \\
\hline & & Total & 42 & 4.31 & 0.75 & 2.67 & 1.41 \\
\hline & \multirow[t]{3}{*}{ Married } & Child-absent & 17 & 4.56 & 0.80 & 4.18 & 1.70 \\
\hline & & Child-present & 18 & 4.50 & 0.84 & 4.00 & 1.75 \\
\hline & & Total & 35 & 4.53 & 0.80 & 4.09 & 1.70 \\
\hline & \multirow[t]{3}{*}{ Total } & Child-absent & 44 & 4.48 & 0.80 & 3.34 & 1.66 \\
\hline & & Child-present & 33 & 4.32 & 0.76 & 3.27 & 1.77 \\
\hline & & Total & 77 & 4.41 & 0.78 & 3.31 & 1.70 \\
\hline \multirow[t]{9}{*}{ Equal $_{\mathrm{f}}$} & \multirow[t]{3}{*}{ Unmarried } & Child-absent & 16 & 5.17 & 1.06 & 3.81 & 1.76 \\
\hline & & Child-present & 23 & 5.00 & 0.89 & 3.74 & 2.07 \\
\hline & & Total & 39 & 5.07 & 0.95 & 3.77 & 1.93 \\
\hline & \multirow[t]{3}{*}{ Married } & Child-absent & 21 & 5.04 & 0.78 & 4.71 & 1.85 \\
\hline & & Child-present & 20 & 5.08 & 0.74 & 5.20 & 1.61 \\
\hline & & Total & 41 & 5.06 & 0.75 & 4.95 & 1.73 \\
\hline & \multirow[t]{3}{*}{ Total } & Child-absent & 37 & 5.10 & 0.90 & 4.32 & 1.84 \\
\hline & & Child-present & 43 & 5.04 & 0.81 & 4.42 & 1.99 \\
\hline & & Total & 80 & 5.06 & 0.85 & 4.38 & 1.91 \\
\hline
\end{tabular}


Table 3 cont

Means and Standard Deviations of CSSD and APS by GRR, Marital Status, and Parental Status

\begin{tabular}{|c|c|c|c|c|c|c|c|}
\hline \multirow[b]{2}{*}{$\mathrm{GRR}_{\mathrm{c}}$} & \multirow[b]{2}{*}{ Marital Status } & \multirow[b]{2}{*}{ Parental Status } & \multirow[b]{2}{*}{$N$} & \multicolumn{2}{|c|}{$\mathrm{CSSD}_{\mathrm{a}}$} & \multicolumn{2}{|c|}{$\mathrm{APS}_{\mathrm{b}}$} \\
\hline & & & & Mean & $\mathrm{SD}$ & Mean & SD \\
\hline \multirow[t]{9}{*}{ Fsenior $_{g}$} & \multirow[t]{3}{*}{ Unmarried } & Child-absent & 23 & 4.53 & 0.87 & 3.65 & 1.94 \\
\hline & & Child-present & 31 & 4.33 & 0.96 & 3.03 & 1.72 \\
\hline & & Total & 54 & 4.41 & 0.92 & 3.30 & 1.83 \\
\hline & \multirow[t]{3}{*}{ Married } & Child-absent & 20 & 4.92 & 0.93 & 4.65 & 1.98 \\
\hline & & Child-present & 17 & 4.81 & 0.98 & 3.18 & 1.85 \\
\hline & & Total & 37 & 4.87 & 0.94 & 3.97 & 2.03 \\
\hline & \multirow[t]{3}{*}{ Total } & Child-absent & 43 & 4.71 & 0.91 & 4.12 & 2.00 \\
\hline & & Child-present & 48 & 4.50 & 0.99 & 3.08 & 1.75 \\
\hline & & Total & 91 & 4.60 & 0.95 & 3.57 & 1.93 \\
\hline \multirow[t]{9}{*}{ Fhead $_{h}$} & \multirow[t]{3}{*}{ Unmarried } & Child-absent & 32 & 4.43 & 1.01 & 2.91 & 1.69 \\
\hline & & Child-present & 21 & 4.40 & 1.31 & 2.71 & 1.85 \\
\hline & & Total & 53 & 4.42 & 1.13 & 2.83 & 1.74 \\
\hline & \multirow[t]{3}{*}{ Married } & Child-absent & 26 & 4.72 & 0.89 & 3.35 & 1.96 \\
\hline & & Child-present & 20 & 4.44 & 0.63 & 3.25 & 1.77 \\
\hline & & Total & 46 & 4.60 & 0.79 & 3.30 & 1.86 \\
\hline & \multirow[t]{3}{*}{ Total } & Child-absent & 58 & 4.56 & 0.96 & 3.10 & 1.81 \\
\hline & & Child-present & 41 & 4.42 & 1.02 & 2.98 & 1.81 \\
\hline & & Total & 99 & 4.50 & 0.99 & 3.05 & 1.80 \\
\hline \multirow[t]{9}{*}{ Total } & \multirow[t]{3}{*}{ Unmarried } & Child-absent & 119 & 4.48 & 0.92 & 3.03 & 1.70 \\
\hline & & Child-present & 111 & 4.45 & 1.01 & 3.06 & 1.86 \\
\hline & & Total & 230 & 4.47 & 0.96 & 3.04 & 1.78 \\
\hline & \multirow[t]{3}{*}{ Married } & Child-absent & 111 & 4.74 & 0.91 & 3.95 & 1.95 \\
\hline & & Child-present & 97 & 4.65 & 0.85 & 3.93 & 1.89 \\
\hline & & Total & 208 & 4.70 & 0.88 & 3.94 & 1.92 \\
\hline & \multirow[t]{3}{*}{ Total } & Child-absent & 230 & 4.60 & 0.92 & 3.47 & 1.88 \\
\hline & & Child-present & 208 & 4.55 & 0.94 & 3.47 & 1.92 \\
\hline & & Total & 438 & 4.58 & 0.93 & 3.47 & 1.90 \\
\hline
\end{tabular}


a. CSSD = Couple Satisfaction Semantic Differential

b. APS = Anticipated Personal Satisfaction

c. GRR = Gender Role Relationship assignment

$\mathrm{d}$. Mhead = Male-head/female-complement gender role relationship assignment

e. Msenior = Male-senior/female-junior gender role relationship assignment

f. Equal = Partner-equal gender role relationship assignment

g. Fsenior $=$ Female-senior/male-junior gender role relationship assignment

h. Fhead $=$ Female-head/male-complement gender role relationship assignment 
Table 4

Multivariate tests for the effects of GRR, Marital Status, and Parental Status on Perceived Satisfaction (N $=438)$

\begin{tabular}{lccccc}
\hline & Wilks' & & & & \\
Effect & Lambda & $F$ & $d f_{1}$ & $d f_{2}$ & $p$ \\
\hline Intercept & .04 & 5730.91 & 2 & 417 & .00 \\
GRR $^{\mathrm{a}}$ & .91 & 5.35 & 8 & 834 & .00 \\
Marital.status & .94 & 14.22 & 2 & 417 & .00 \\
Parental.status & 1.00 & .49 & 2 & 417 & .61 \\
GRR $^{\mathrm{a}}$ x Marital.status & .97 & 1.64 & 8 & 834 & .11 \\
GRR $^{\mathrm{a}}$ x Parental.status & .97 & 1.89 & 8 & 834 & .06 \\
\hline
\end{tabular}

a. GRR = Gender Role Relationship assignment 


\section{Table 5}

Univariate tests for the effect of GRR on Perceived Satisfaction $(N=438)$

\begin{tabular}{|c|c|c|c|c|c|}
\hline Source & DV & Mean Square & $F$ & $d f$ & $P$ \\
\hline \multirow[t]{2}{*}{ Intercept } & $\mathrm{CSSD}^{\mathrm{a}}$ & 8860.15 & 10868.82 & 1 & .00 \\
\hline & $\mathrm{APS}^{\mathrm{b}}$ & 5170.60 & 1622.82 & 1 & .00 \\
\hline $\mathrm{GRR}^{\mathrm{c}}$ & $\operatorname{CSSD}^{\mathrm{a}}$ & 6.98 & 8.56 & 4 & .00 \\
\hline \multirow[t]{2}{*}{ Marital.status } & $\mathrm{CSSD}^{\mathrm{a}}$ & 5.34 & 6.56 & 1 & .01 \\
\hline & $\mathrm{APS}^{\mathrm{b}}$ & 89.54 & 28.10 & 1 & .00 \\
\hline
\end{tabular}

a. CSSD = Couple Satisfaction Semantic Differential

b. APS = Anticipated Personal Satisfaction

c. GRR = Gender Role Relationship assignment 
Table 6

Mean difference tests for the effect of GRR on CSSD $(N=438)$

\begin{tabular}{|c|c|c|c|c|c|c|}
\hline \multirow[b]{2}{*}{$\mathrm{GRR}^{\mathrm{a}}$} & & \multirow[b]{2}{*}{ Mean difference } & \multirow[b]{2}{*}{$\mathrm{SE}$} & \multirow[b]{2}{*}{$p$} & \multicolumn{2}{|c|}{$95 \% \mathrm{CI}$} \\
\hline & & & & & Lower & Upper \\
\hline \multirow[t]{4}{*}{ Mhead $^{\mathrm{b}}$} & Msenior $^{\mathrm{c}}$ & -.06 & .14 & .99 & -.45 & .32 \\
\hline & Equal $^{\mathrm{d}}$ & -.72 & .14 & .00 & -1.10 & -.34 \\
\hline & Fsenior $^{\mathrm{e}}$ & -.25 & .13 & .33 & -.62 & .11 \\
\hline & Fhead $^{\mathrm{f}}$ & -.15 & .13 & .77 & -.51 & .21 \\
\hline \multirow[t]{4}{*}{ Msenior $^{\mathrm{c}}$} & Mhead $^{\mathrm{b}}$ & .06 & .14 & .99 & -.32 & .45 \\
\hline & Equal $^{\mathrm{d}}$ & -.65 & .14 & .00 & -1.05 & -.26 \\
\hline & Fsenior $^{\mathrm{e}}$ & -.19 & .14 & .66 & -.57 & .19 \\
\hline & Fhead $^{\mathrm{f}}$ & -.09 & .14 & .97 & -.47 & .29 \\
\hline \multirow[t]{4}{*}{ Equal $^{\mathrm{d}}$} & Mhead $^{\mathrm{b}}$ & .72 & .14 & .00 & .34 & 1.10 \\
\hline & Msenior $^{c}$ & .65 & .14 & .00 & .26 & 1.05 \\
\hline & Fsenior $^{\mathrm{e}}$ & .46 & .14 & .01 & .09 & .84 \\
\hline & Fhead $^{\mathrm{f}}$ & .56 & .14 & .00 & .19 & .94 \\
\hline \multirow[t]{4}{*}{ Fsenior $^{\mathrm{e}}$} & Mhead $^{\mathrm{b}}$ & .25 & .13 & .33 & -.11 & .62 \\
\hline & Msenior $^{\mathrm{c}}$ & .19 & .14 & .66 & -.20 & .57 \\
\hline & Equal $^{\mathrm{d}}$ & -.46 & .14 & .01 & -.84 & -.09 \\
\hline & Fhead $^{\mathrm{f}}$ & .10 & .13 & .94 & -.26 & .46 \\
\hline \multirow[t]{4}{*}{ Fhead $^{\mathrm{f}}$} & Mhead $^{\mathrm{b}}$ & .15 & .13 & .77 & -.21 & .51 \\
\hline & Msenior $^{\mathrm{c}}$ & .09 & .14 & .97 & -.29 & .47 \\
\hline & Equal $^{\mathrm{d}}$ & -.56 & .14 & .00 & -.94 & -.19 \\
\hline & Fsenior $^{\mathrm{e}}$ & -.10 & .13 & .94 & -.46 & .26 \\
\hline
\end{tabular}

a. $\mathrm{GRR}=$ Gender Role Relationship assignment

b. Mhead = Male-head/female-complement gender role relationship assignment

c. Msenior = Male-senior/female-junior gender role relationship assignment

d. Equal = Partner-equal gender role relationship assignment

e. Fsenior = Female-senior/male-junior gender role relationship assignment

$\mathrm{f}$. Fhead = Female-head/male-complement gender role relationship assignment 
Table 7

Mean difference tests for the effect of GRR on APS $(N=438)$

\begin{tabular}{|c|c|c|c|c|c|c|}
\hline \multirow[b]{2}{*}{$\mathrm{GRR}^{\mathrm{a}}$} & & \multirow[b]{2}{*}{ Mean difference } & \multirow[b]{2}{*}{$\mathrm{SE}$} & \multirow[b]{2}{*}{$p$} & \multicolumn{2}{|c|}{$95 \% \mathrm{CI}$} \\
\hline & & & & & Lower & Upper \\
\hline \multirow[t]{4}{*}{ Mhead $^{\mathrm{b}}$} & Msenior $^{\mathrm{c}}$ & -.16 & .28 & .98 & -.92 & .60 \\
\hline & Equal $^{\mathrm{d}}$ & -1.22 & .27 & .00 & -1.97 & -.47 \\
\hline & Fsenior $^{\mathrm{e}}$ & -.42 & .26 & .51 & -1.14 & .31 \\
\hline & Fhead $^{\mathrm{f}}$ & .10 & .26 & 1.00 & -.61 & .81 \\
\hline \multirow[t]{4}{*}{ Msenior $^{\mathrm{c}}$} & Mhead $^{\mathrm{b}}$ & .16 & .28 & .98 & -.60 & .92 \\
\hline & Equal $^{\mathrm{d}}$ & -1.06 & .28 & .00 & -1.84 & -.28 \\
\hline & Fsenior $^{\mathrm{e}}$ & -.26 & .28 & .88 & -1.02 & .50 \\
\hline & Fhead $^{\mathrm{f}}$ & .26 & .27 & .87 & -.48 & 1.00 \\
\hline \multirow[t]{4}{*}{ Equal $^{\mathrm{d}}$} & Mhead $^{\mathrm{b}}$ & 1.22 & .27 & .00 & .47 & 1.97 \\
\hline & Msenior $^{\mathrm{c}}$ & 1.06 & .28 & .00 & .28 & 1.84 \\
\hline & Fsenior $^{\mathrm{e}}$ & .80 & .27 & .03 & .05 & 1.55 \\
\hline & Fhead $^{\mathrm{f}}$ & 1.32 & .27 & .00 & .59 & 2.06 \\
\hline \multirow[t]{4}{*}{ Fsenior $^{\mathrm{e}}$} & Mhead $^{\mathrm{b}}$ & .42 & .26 & .51 & -.31 & 1.14 \\
\hline & Msenior $^{c}$ & .26 & .28 & .88 & -.50 & 1.02 \\
\hline & Equal $^{\mathrm{d}}$ & -.80 & .27 & .03 & -1.55 & -.05 \\
\hline & Fhead $^{\mathrm{f}}$ & .52 & .26 & .26 & -.19 & 1.23 \\
\hline \multirow[t]{4}{*}{ Fhead $^{\mathrm{f}}$} & Mhead $^{\mathrm{b}}$ & -.10 & .26 & 1.00 & -.81 & .61 \\
\hline & Msenior $^{c}$ & -.26 & .27 & .87 & -1.00 & .48 \\
\hline & Equal $^{\mathrm{d}}$ & -1.32 & .27 & .00 & -2.06 & -.59 \\
\hline & Fsenior $^{\mathrm{e}}$ & -.52 & .26 & .26 & -1.23 & .19 \\
\hline
\end{tabular}

a. GRR = Gender Role Relationship assignment

b. Mhead = Male-head/female-complement gender role relationship assignment

c. Msenior = Male-senior/female-junior gender role relationship assignment

d. Equal $=$ Partner-equal gender role relationship assignment

e. Fsenior = Female-senior/male-junior gender role relationship assignment

$\mathrm{f}$. Fhead $=$ Female-head/male-complement gender role relationship assignment 
Table 8

Male-Head/Female-Complement GRR Regression Analyses

\begin{tabular}{|c|c|c|c|c|c|c|c|}
\hline \multirow[b]{2}{*}{ Predicto } & & \multicolumn{3}{|c|}{$\mathrm{CSSD}^{\mathrm{a}}$} & \multicolumn{3}{|c|}{$\mathrm{APS}^{\mathrm{b}}$} \\
\hline & & $B$ & $S E B$ & $\beta$ & $B$ & $S E B$ & $\beta$ \\
\hline Step 1 & Parental Status & .10 & .19 & .06 & .77 & .38 & $.21 *$ \\
\hline \multirow[t]{4}{*}{ Step 2} & Gender & .00 & .27 & .00 & -.41 & .54 & -.08 \\
\hline & Religiosity & -.02 & .10 & -.02 & -.13 & .20 & -.07 \\
\hline & Income & .12 & .05 & $.30 *$ & .08 & .10 & .10 \\
\hline & Parents' marital status & -.08 & .24 & -.04 & .14 & .49 & .03 \\
\hline \multicolumn{2}{|c|}{ Total $R^{2}$} & & .11 & & & .15 & \\
\hline
\end{tabular}

$* p<.05 . * * p<.01$

a. CSSD = Couple Satisfaction Semantic Differential, $N=89$

b. APS = Anticipated Personal Satisfaction. $N=90$ 
Table 9

Male-Senior/Female-Junior GRR Regression Analyses

\begin{tabular}{|c|c|c|c|c|c|c|c|}
\hline \multirow{2}{*}{\multicolumn{2}{|c|}{ Predictor }} & \multicolumn{3}{|c|}{$\operatorname{CSSD}^{\mathrm{a}}$} & \multicolumn{3}{|c|}{$\mathrm{APS}^{\mathrm{b}}$} \\
\hline & & $B$ & $S E B$ & $\beta$ & $B$ & $S E B$ & $\beta$ \\
\hline & Parental Status & -.20 & .18 & -.13 & -.29 & .35 & -.09 \\
\hline \multirow[t]{4}{*}{ Step 2} & Gender & -.10 & .28 & -.04 & -1.31 & .51 & $-.28 *$ \\
\hline & Religiosity & .04 & .09 & .05 & .09 & .17 & .05 \\
\hline & Income & -.01 & .05 & -.02 & -.17 & .10 & -.23 \\
\hline & Parents' marital status & .17 & .23 & .10 & .54 & .44 & .15 \\
\hline \multicolumn{2}{|c|}{ Total $R^{2}$} & & .13 & & & $.28 *$ & \\
\hline
\end{tabular}

$p<.05 .{ }^{* *} p<.01$.

a. CSSD = Couple Satisfaction Semantic Differential, $N=76$

b. APS = Anticipated Personal Satisfaction, $N=80$ 
Table 10

Partner-Equal GRR Regression Analyses

\begin{tabular}{|c|c|c|c|c|c|c|c|}
\hline & & \multicolumn{3}{|c|}{$\mathrm{CSSD}^{\mathrm{a}}$} & \multicolumn{3}{|c|}{$\mathrm{APS}^{\mathrm{b}}$} \\
\hline Predic & & $B$ & $S E B$ & $\beta$ & $B$ & $S E B$ & $\beta$ \\
\hline & Parental Status & -.06 & .20 & -.04 & .32 & .41 & .08 \\
\hline \multirow[t]{4}{*}{ Step 2} & Gender & -.23 & .27 & -.11 & -.15 & .55 & -.03 \\
\hline & Religiosity & -.06 & .10 & -.08 & -.36 & .21 & -.19 \\
\hline & Income & .08 & .05 & .18 & .07 & .11 & .07 \\
\hline & Parents' marital status & -.40 & .24 & -.20 & -.86 & .50 & -.19 \\
\hline \multicolumn{2}{|c|}{ Total $R^{2}$} & & .07 & & & .18 & \\
\hline
\end{tabular}

* $*$ < $<.05 . * * p<.01$

a. CSSD = Couple Satisfaction Semantic Differential. $N=78$

b. APS = Anticipated Personal Satisfaction, $N=81$ 
Table 11

Female-Senior/Male-Junior GRR Regression Analyses

\begin{tabular}{|c|c|c|c|c|c|c|c|}
\hline \multirow{2}{*}{\multicolumn{2}{|c|}{ Predictor }} & \multicolumn{3}{|c|}{$\mathrm{CSSD}^{\mathrm{a}}$} & \multicolumn{3}{|c|}{$\mathrm{APS}^{\mathrm{b}}$} \\
\hline & & $B$ & $S E B$ & $\beta$ & $B$ & $S E B$ & $\beta$ \\
\hline & Parental Status & -.23 & .20 & -.12 & -1.01 & .40 & $-.26^{*}$ \\
\hline \multirow[t]{4}{*}{ Step 2} & Gender & -.43 & .35 & -.13 & -.55 & .67 & -.08 \\
\hline & Religiosity & -.26 & .10 & $-.28 * *$ & -.72 & .18 & $-.37 * *$ \\
\hline & Income & -.09 & .05 & -.20 & .23 & .09 & $-.25^{*}$ \\
\hline & Parents' marital status & -.02 & .22 & -.01 & .29 & .41 & .07 \\
\hline \multicolumn{2}{|c|}{ Total $R^{2}$} & & $.19 *$ & & & $.31 * *$ & \\
\hline
\end{tabular}

๘ $* p<.05$. ** $p<.01$.

a. CSSD = Couple Satisfaction Semantic Differential, $N=87$

b. APS = Anticipated Personal Satisfaction, $N=81$ 
Table 12

Female-Head/Male-Complement GRR Regression Analyses

\begin{tabular}{|c|c|c|c|c|c|c|c|}
\hline \multirow{2}{*}{\multicolumn{2}{|c|}{ Predictor }} & \multicolumn{3}{|c|}{$\mathrm{CSSD}^{\mathrm{a}}$} & \multicolumn{3}{|c|}{$\mathrm{APS}^{\mathrm{b}}$} \\
\hline & & $B$ & $S E B$ & $\beta$ & $B$ & $S E B$ & $\beta$ \\
\hline & Parental Status & -.05 & .21 & -.02 & .11 & .38 & .03 \\
\hline \multirow[t]{4}{*}{ Step 2} & Gender & .20 & .32 & .07 & .16 & .53 & .03 \\
\hline & Religiosity & -.14 & .10 & -.15 & -.62 & .18 & $-.36 * *$ \\
\hline & Income & .03 & .05 & .06 & .07 & .09 & .08 \\
\hline & Parents' marital status & -.14 & .24 & -.06 & -.24 & .40 & -.06 \\
\hline \multicolumn{2}{|c|}{ Total $R^{2}$} & & .06 & & & $.17 * *$ & \\
\hline
\end{tabular}

$\stackrel{6}{t}$

$p<.05 . * * p<.01$

a. CSSD $=$ Couple Satisfaction Semantic Differential, $N=93$

b. APS $=$ Anticipated Personal Satisfaction, $N=88$ 


\section{Table 13}

\section{Qualitative Codes and Examples Derived from Respondents' CSSD and APS Responses}

\begin{tabular}{|c|c|}
\hline Rationale/Code & Example responses \\
\hline Positively relating the scenario to own desires or experiences & "My parents both work full time and were equally involved in my life." \\
\hline Negatively relating the scenario to own desires or experiences & "I do not think this could work $100 \%$ for me...that's because of my upbringing." \\
\hline Preference for an equal-partner $G_{R R}{ }^{a}$ & "A satisfying relationship would be one where we both work full-time and contribute equally to the house." \\
\hline Projecting happiness/strength/functionality & "They have a structure, seem to respect one another, and are fair." \\
\hline Negative view of cohabitation before marriage & "I believe cohabitation before marriage is a bad idea." \\
\hline Preference for a conventional GRR ${ }^{\mathrm{a}}$ & "I would like for my husband to provide and care for me...financially." \\
\hline Work-personal life balances & "Sounds like they are very involved in their work. I imagine them not spending a lot of time together." \\
\hline Projecting conflict/dysfunction/stress on the couple & "I would guess... a stressful relationship where satisfaction is more difficult." \\
\hline Negative view of child-free couples & "They have no children...There would be no excitement and no fun." \\
\hline Emasculation in nonconventional GRRs ${ }^{\mathrm{a}}$ & "The man is not making the most money in the household, and that can be a security issue for the man." \\
\hline Presence of a successful career & "Having an executive job would be worthwhile." \\
\hline Society's view of the scenario & "I think that their situation is not condoned by society." \\
\hline Power imbalance among the spouses & "Joe may resent having no/little decision-making power." \\
\hline Projecting laziness on partner not working & "Courtney has nothing to do all day so she appears lazy." \\
\hline Preference for a nonconventional GRR ${ }^{\mathrm{a}}$ & "I really want to have a career...I'd be thrilled to have a stay-at-home husband." \\
\hline Positive view of child-free couples & "As they do not have children, they can afford to spend more quality time together." \\
\hline Basing answer on religious beliefs & "The relationship is sinful according to the Bible." \\
\hline Having a financial responsibility to provide for spouse & "One person does all the housework and the other provides financially. It seems like a fair trade-off." \\
\hline Not having a financial responsibility to provide for spouse & "Joe has no financial responsibility to her since they are not married." \\
\hline A partner or partners providing enough income to the family & "The husband has a steady, decent income. Enough so that the wife does not need to work." \\
\hline A partner or partners not providing enough income to the family & "It may be less stressful if my partner made some income, just considering the economy." \\
\hline Achieving financial independence by working & "The mother is obtaining some independence by getting a part time job." \\
\hline
\end{tabular}

a. GRR = Gender Role Relationship 
Table 14

Rationale for Respondents' CSSD Responses based on GRR Assignment $(N=421)$

\begin{tabular}{|c|c|c|c|c|c|c|}
\hline \multirow[b]{2}{*}{ Rationale/Code } & \multicolumn{6}{|c|}{$N$} \\
\hline & $\begin{array}{l}\text { Male- } \\
\text { Head }\end{array}$ & $\begin{array}{l}\text { Male- } \\
\text { Senior }\end{array}$ & $\begin{array}{c}\text { Partner- } \\
\text { Equal }\end{array}$ & $\begin{array}{c}\text { Female- } \\
\text { Senior }\end{array}$ & $\begin{array}{c}\text { Female- } \\
\text { Head }\end{array}$ & Total \\
\hline Positively relating the scenario to own desires or experiences & 16 & 18 & 11 & 18 & 20 & 83 \\
\hline Negatively relating the scenario to own desires or experiences & 55 & 49 & 53 & 50 & 69 & 276 \\
\hline Preference for an equal-partner GRR ${ }^{a}$ & 54 & 43 & 14 & 41 & 42 & 194 \\
\hline Projecting happiness/strength/functionality & 24 & 25 & 36 & 27 & 28 & 140 \\
\hline Negative view of cohabitation before marriage & 16 & 12 & 21 & 17 & 13 & 79 \\
\hline Not enough information to determine & 19 & 16 & 13 & 10 & 20 & 78 \\
\hline Preference for a conventional GRR ${ }^{a}$ & 14 & 5 & 5 & 20 & 22 & 66 \\
\hline Work-personal life balances & 10 & 13 & 24 & 12 & 4 & 63 \\
\hline Projecting conflict/dysfunction/stress on the couple & 11 & 8 & 5 & 10 & 12 & 46 \\
\hline Negative view of child-free couples & 12 & 2 & 13 & 2 & 6 & 35 \\
\hline Emasculation in nonconventional GRRs ${ }^{\mathrm{a}}$ & 1 & 0 & 0 & 17 & 15 & 33 \\
\hline Presence of a successful career & 6 & 4 & 14 & 4 & 5 & 33 \\
\hline $\mathrm{GRR}^{\mathrm{a}}$ is too boring/consistent/rigid & 8 & 4 & 12 & 1 & 4 & 29 \\
\hline Society's view of the scenario & 3 & 4 & 3 & 4 & 9 & 23 \\
\hline Power imbalance among the spouses & 7 & 3 & 1 & 4 & 1 & 16 \\
\hline Projecting laziness on partner not working & 5 & 1 & 0 & 3 & 5 & 14 \\
\hline Preference for a nonconventional GRR ${ }^{\mathrm{a}}$ & 1 & 0 & 0 & 7 & 5 & 13 \\
\hline Positive view of child-free couples & 1 & 3 & 2 & 1 & 1 & 8 \\
\hline Basing answer on religious beliefs & 4 & 0 & 2 & 0 & 1 & 7 \\
\hline
\end{tabular}


Table 14 cont.

Rationale for Respondents' CSSD Responses based on GRR Assignment $(N=421)$

\begin{tabular}{|c|c|c|c|c|c|c|}
\hline \multirow[b]{2}{*}{ Rationale/Code } & \multicolumn{6}{|c|}{$N$} \\
\hline & $\begin{array}{l}\text { Male- } \\
\text { Head } \\
\end{array}$ & $\begin{array}{l}\text { Male- } \\
\text { Senior }\end{array}$ & $\begin{array}{c}\text { Partner- } \\
\text { Equal } \\
\end{array}$ & $\begin{array}{c}\text { Female- } \\
\text { Senior } \\
\end{array}$ & $\begin{array}{c}\text { Female- } \\
\text { Head }\end{array}$ & Total \\
\hline Having a financial responsibility to provide for spouse & 0 & 0 & 1 & 0 & 2 & 3 \\
\hline Not having a financial responsibility to provide for spouse & 2 & 4 & 2 & 2 & 1 & 11 \\
\hline A partner or partners providing enough income to the family & 12 & 7 & 9 & 16 & 16 & 60 \\
\hline A partner or partners not providing enough income to the family & 4 & 5 & 5 & 6 & 5 & 25 \\
\hline Achieving financial independence by working & 2 & 1 & 1 & 0 & 1 & 5 \\
\hline Not achieving financial independence because not working & 4 & 3 & 4 & 3 & 3 & 17 \\
\hline Answer based on research & 1 & 1 & 0 & 2 & 0 & 4 \\
\hline Total & 292 & 231 & 251 & 277 & 310 & 1361 \\
\hline
\end{tabular}

a. GRR = Gender Role Relationship 
Table 15

Rationale for Respondents' APS Responses based on GRR Assignment $(N=413)$

\begin{tabular}{|c|c|c|c|c|c|c|}
\hline \multirow[b]{2}{*}{ Rationale/Code } & \multicolumn{6}{|c|}{$N$} \\
\hline & $\begin{array}{l}\text { Male- } \\
\text { Head }\end{array}$ & $\begin{array}{l}\text { Male- } \\
\text { Senior }\end{array}$ & $\begin{array}{c}\text { Partner- } \\
\text { Equal }\end{array}$ & $\begin{array}{c}\text { Female- } \\
\text { Senior }\end{array}$ & $\begin{array}{c}\text { Female- } \\
\text { Head }\end{array}$ & Total \\
\hline Positively relating the scenario to own desires or experiences & 20 & 18 & 12 & 20 & 21 & 91 \\
\hline Negatively relating the scenario to own desires or experiences & 59 & 51 & 55 & 59 & 72 & 296 \\
\hline Preference for an equal-partner GRR ${ }^{a}$ & 51 & 43 & 13 & 39 & 46 & 192 \\
\hline Projecting happiness/strength/functionality & 2 & 7 & 7 & 7 & 5 & 28 \\
\hline Negative view of cohabitation before marriage & 14 & 12 & 23 & 14 & 10 & 73 \\
\hline Not enough information to determine & 1 & 1 & 3 & 1 & 6 & 12 \\
\hline Preference for a conventional GRR ${ }^{a}$ & 15 & 4 & 5 & 19 & 22 & 65 \\
\hline Work-personal life balances & 5 & 5 & 15 & 10 & 3 & 38 \\
\hline Projecting conflict/dysfunction/stress on the couple & 6 & 2 & 3 & 4 & 5 & 20 \\
\hline Negative view of child-free couples & 9 & 1 & 16 & 3 & 6 & 35 \\
\hline Emasculation in nonconventional GRRs ${ }^{\mathrm{a}}$ & 1 & 0 & 0 & 3 & 0 & 4 \\
\hline Presence of a successful career & 5 & 4 & 6 & 6 & 4 & 25 \\
\hline $\mathrm{GRR}^{\mathrm{a}}$ is too boring/consistent/rigid & 7 & 2 & 11 & 0 & 2 & 22 \\
\hline Society's view of the scenario & 0 & 1 & 2 & 2 & 2 & 7 \\
\hline Power imbalance among the spouses & 4 & 2 & 0 & 4 & 0 & 10 \\
\hline Projecting laziness on partner not working & 3 & 1 & 0 & 0 & 2 & 6 \\
\hline Preference for a nonconventional GRR ${ }^{\mathrm{a}}$ & 2 & 0 & 1 & 9 & 5 & 17 \\
\hline Positive view of child-free couples & 2 & 3 & 1 & 1 & 1 & 8 \\
\hline Basing answer on religious beliefs & 3 & 0 & 0 & 0 & 1 & 4 \\
\hline
\end{tabular}


Table 15 cont.

Rationale for Respondents' APS Responses based on GRR Assignment $(N=413)$

\begin{tabular}{|c|c|c|c|c|c|c|}
\hline \multirow[b]{2}{*}{ Rationale/Code } & \multicolumn{6}{|c|}{$N$} \\
\hline & $\begin{array}{l}\text { Male- } \\
\text { Head } \\
\end{array}$ & $\begin{array}{l}\text { Male- } \\
\text { Senior }\end{array}$ & $\begin{array}{c}\text { Partner- } \\
\text { Equal } \\
\end{array}$ & $\begin{array}{c}\text { Female- } \\
\text { Senior } \\
\end{array}$ & $\begin{array}{c}\text { Female- } \\
\text { Head }\end{array}$ & Total \\
\hline Having a financial responsibility to provide for spouse & 0 & 0 & 0 & 1 & 1 & 2 \\
\hline Not having a financial responsibility to provide for spouse & 2 & 3 & 0 & 1 & 0 & 6 \\
\hline A partner or partners providing enough income to the family & 6 & 5 & 10 & 9 & 10 & 40 \\
\hline A partner or partners not providing enough income to the family & 6 & 6 & 2 & 6 & 5 & 25 \\
\hline Achieving financial independence by working & 2 & 0 & 1 & 0 & 0 & 3 \\
\hline Not achieving financial independence because not working & 4 & 2 & 2 & 3 & 3 & 14 \\
\hline Answer based on research & 0 & 0 & 0 & 1 & 0 & 1 \\
\hline Total & 229 & 173 & 188 & 222 & 232 & 1044 \\
\hline
\end{tabular}

a. GRR = Gender Role Relationship 
Table 16

Rationale for Respondents' CSSD Responses based on Marital Status Assignment $(N=421)$

\begin{tabular}{|c|c|c|c|}
\hline \multirow[b]{2}{*}{ Rationale/Code } & \multicolumn{3}{|c|}{$N$} \\
\hline & Married & Cohabitating & Total \\
\hline Positively relating the scenario to own desires or experiences & 33 & 50 & 83 \\
\hline Negatively relating the scenario to own desires or experiences & 138 & 138 & 276 \\
\hline Preference for an equal-partner GRR ${ }^{\mathrm{a}}$ & 91 & 103 & 194 \\
\hline Projecting happiness/strength/functionality & 71 & 69 & 140 \\
\hline Negative view of cohabitation before marriage & 0 & 79 & 79 \\
\hline Not enough information to determine & 41 & 37 & 78 \\
\hline Preference for a conventional GRR ${ }^{a}$ & 43 & 23 & 66 \\
\hline Work-personal life balances & 33 & 30 & 63 \\
\hline Projecting conflict/dysfunction/stress on the couple & 24 & 22 & 46 \\
\hline Negative view of child-free couples & 22 & 13 & 35 \\
\hline Emasculation in nonconventional GRRs ${ }^{\mathrm{a}}$ & 15 & 18 & 33 \\
\hline Presence of a successful career & 22 & 11 & 33 \\
\hline $\mathrm{GRR}^{\mathrm{a}}$ is too boring/consistent/rigid & 16 & 13 & 29 \\
\hline Society's view of the scenario & 11 & 12 & 23 \\
\hline Power imbalance among the spouses & 9 & 7 & 16 \\
\hline Projecting laziness on partner not working & 6 & 8 & 14 \\
\hline Preference for a nonconventional GRR ${ }^{\mathrm{a}}$ & 7 & 6 & 13 \\
\hline Positive view of child-free couples & 4 & 4 & 8 \\
\hline Basing answer on religious beliefs & 3 & 4 & 7 \\
\hline Having a financial responsibility to provide for spouse & 1 & 2 & 3 \\
\hline
\end{tabular}


Table 16 cont.

Rationale for Respondents' CSSD Responses based on Marital Status Assignment $(N=421)$

\begin{tabular}{lccc}
\hline & & $N$ & \\
Rationale/Code & Married & Cohabitating & Total \\
\hline Not having a financial responsibility to provide for spouse & 7 & 4 & 11 \\
A partner or partners providing enough income to the family & 35 & 25 & 60 \\
A partner or partners not providing enough income to the family & 13 & 12 & 25 \\
Achieving financial independence by working & 5 & 0 & 5 \\
Not achieving financial independence because not working & 9 & 8 & 17 \\
Answer based on research & 3 & 1 & 4 \\
\hline Total & 662 & 699 & 1361 \\
\hline
\end{tabular}

a. GRR = Gender Role Relationship 
Table 17

Rationale for Respondents' APS Responses based on Marital Status Assignment $(N=413)$

\begin{tabular}{|c|c|c|c|}
\hline \multirow[b]{2}{*}{ Rationale/Code } & \multicolumn{3}{|c|}{$N$} \\
\hline & Married & Cohabitating & Total \\
\hline Positively relating the scenario to own desires or experiences & 37 & 54 & 91 \\
\hline Negatively relating the scenario to own desires or experiences & 150 & 146 & 296 \\
\hline Preference for an equal-partner $\mathrm{GRR}^{\mathrm{a}}$ & 83 & 109 & 192 \\
\hline Projecting happiness/strength/functionality & 18 & 10 & 28 \\
\hline Negative view of cohabitation before marriage & 3 & 70 & 73 \\
\hline Not enough information to determine & 7 & 5 & 12 \\
\hline Preference for a conventional GRR ${ }^{\mathrm{a}}$ & 46 & 19 & 65 \\
\hline Work-personal life balances & 23 & 15 & 38 \\
\hline Projecting conflict/dysfunction/stress on the couple & 7 & 13 & 20 \\
\hline Negative view of child-free couples & 20 & 15 & 35 \\
\hline Emasculation in nonconventional GRRs ${ }^{\mathrm{a}}$ & 4 & 0 & 4 \\
\hline Presence of a successful career & 17 & 8 & 25 \\
\hline $\mathrm{GRR}^{\mathrm{a}}$ is too boring/consistent/rigid & 13 & 9 & 22 \\
\hline Society's view of the scenario & 3 & 4 & 7 \\
\hline Power imbalance among the spouses & 6 & 4 & 10 \\
\hline Projecting laziness on partner not working & 3 & 3 & 6 \\
\hline Preference for a nonconventional GRR ${ }^{\mathrm{a}}$ & 10 & 7 & 17 \\
\hline Positive view of child-free couples & 3 & 5 & 8 \\
\hline Basing answer on religious beliefs & 0 & 4 & 4 \\
\hline Having a financial responsibility to provide for spouse & 1 & 1 & 2 \\
\hline
\end{tabular}


Table 17 cont.

Rationale for Respondents' APS Responses based on Marital Status Assignment $(N=413)$

\begin{tabular}{lccc}
\hline & & $N$ & \\
Rationale/Code & Married & Cohabitating & Total \\
\hline Not having a financial responsibility to provide for spouse & 3 & 3 & 6 \\
A partner or partners providing enough income to the family & 22 & 18 & 40 \\
A partner or partners not providing enough income to the family & 13 & 12 & 25 \\
Achieving financial independence by working & 3 & 0 & 3 \\
Not achieving financial independence because not working & 8 & 6 & 14 \\
Answer based on research & 1 & 0 & 1 \\
\hline Total & 504 & 540 & 1044 \\
\hline
\end{tabular}

a. $\mathrm{GRR}=$ Gender Role Relationship 
Table 18

Rationale for Respondents' CSSD Responses based on Parental Status Assignment $(N=421)$

\begin{tabular}{|c|c|c|c|}
\hline \multirow[b]{2}{*}{ Rationale/Code } & \multicolumn{3}{|c|}{$N$} \\
\hline & Child-Present & Child-Absent & Total \\
\hline Positively relating the scenario to own desires or experiences & 35 & 48 & 83 \\
\hline Negatively relating the scenario to own desires or experiences & 137 & 139 & 276 \\
\hline Preference for an equal-partner GRR ${ }^{\mathrm{a}}$ & 92 & 102 & 194 \\
\hline Projecting happiness/strength/functionality & 73 & 67 & 140 \\
\hline Negative view of cohabitation before marriage & 40 & 39 & 79 \\
\hline Not enough information to determine & 34 & 44 & 78 \\
\hline Preference for a conventional GRR ${ }^{\mathrm{a}}$ & 36 & 30 & 66 \\
\hline Work-personal life balances & 34 & 29 & 63 \\
\hline Projecting conflict/dysfunction/stress on the couple & 25 & 21 & 46 \\
\hline Negative view of child-free couples & 1 & 34 & 35 \\
\hline Emasculation in nonconventional GRRs ${ }^{\mathrm{a}}$ & 15 & 18 & 33 \\
\hline Presence of a successful career & 16 & 17 & 33 \\
\hline $\mathrm{GRR}^{\mathrm{a}}$ is too boring/consistent/rigid & 10 & 19 & 29 \\
\hline Society's view of the scenario & 13 & 10 & 23 \\
\hline Power imbalance among the spouses & 8 & 8 & 16 \\
\hline Projecting laziness on partner not working & 1 & 13 & 14 \\
\hline Preference for a nonconventional GRR ${ }^{\mathrm{a}}$ & 5 & 8 & 13 \\
\hline Positive view of child-free couples & 2 & 6 & 8 \\
\hline Basing answer on religious beliefs & 2 & 5 & 7 \\
\hline Having a financial responsibility to provide for spouse & 1 & 2 & 3 \\
\hline
\end{tabular}


Table 18 cont.

Rationale for Respondents' CSSD Responses based on Parental Status Assignment $(N=421)$

\begin{tabular}{lccc}
\hline & & $N$ & \\
& & & \\
\cline { 2 - 3 } Rationale/Code & Child-Present & Child-Absent & Total \\
\hline Not having a financial responsibility to provide for spouse & 5 & 6 & 11 \\
A partner or partners providing enough income to the family & 27 & 33 & 60 \\
A partner or partners not providing enough income to the family & 10 & 15 & 25 \\
Achieving financial independence by working & 2 & 3 & 17 \\
Not achieving financial independence because not working & 8 & 9 & 4 \\
Answer based on research & 3 & 1 & 1361 \\
\hline
\end{tabular}

a. GRR = Gender Role Relationship 
Table 19

Rationale for Respondents' APS Responses based on Parental Status Assignment $(N=413)$

\begin{tabular}{|c|c|c|c|}
\hline \multirow[b]{2}{*}{ Rationale/Code } & \multicolumn{3}{|c|}{$N$} \\
\hline & Child-Present & Child-Absent & Total \\
\hline Positively relating the scenario to own desires or experiences & 39 & 52 & 91 \\
\hline Negatively relating the scenario to own desires or experiences & 148 & 148 & 296 \\
\hline Preference for an equal-partner $G_{R R}{ }^{a}$ & 91 & 101 & 192 \\
\hline Projecting happiness/strength/functionality & 14 & 14 & 28 \\
\hline Negative view of cohabitation before marriage & 38 & 35 & 73 \\
\hline Not enough information to determine & 2 & 10 & 12 \\
\hline Preference for a conventional GRR ${ }^{\mathrm{a}}$ & 34 & 31 & 65 \\
\hline Work-personal life balances & 23 & 15 & 38 \\
\hline Projecting conflict/dysfunction/stress on the couple & 8 & 12 & 20 \\
\hline Negative view of child-free couples & 2 & 33 & 35 \\
\hline Emasculation in nonconventional GRRs ${ }^{\mathrm{a}}$ & 2 & 2 & 4 \\
\hline Presence of a successful career & 13 & 12 & 25 \\
\hline $\mathrm{GRR}^{\mathrm{a}}$ is too boring/consistent/rigid & 9 & 13 & 22 \\
\hline Society's view of the scenario & 5 & 2 & 7 \\
\hline Power imbalance among the spouses & 7 & 3 & 10 \\
\hline Projecting laziness on partner not working & 0 & 6 & 6 \\
\hline Preference for a nonconventional GRR ${ }^{\mathrm{a}}$ & 8 & 9 & 17 \\
\hline Positive view of child-free couples & 3 & 5 & 8 \\
\hline Basing answer on religious beliefs & 0 & 4 & 4 \\
\hline Having a financial responsibility to provide for spouse & 1 & 1 & 2 \\
\hline
\end{tabular}


Table 19 cont.

Rationale for Respondents' APS Responses based on Parental Status Assignment $(N=413)$

\begin{tabular}{lccc}
\hline & & & \\
& & & \\
\cline { 2 - 3 } Rationale/Code & Child-Present & Child-Absent & Total \\
\hline Not having a financial responsibility to provide for spouse & 2 & 4 & 6 \\
A partner or partners providing enough income to the family & 16 & 24 & 40 \\
A partner or partners not providing enough income to the family & 11 & 14 & 25 \\
Achieving financial independence by working & 1 & 2 & 3 \\
Not achieving financial independence because not working & 7 & 7 & 14 \\
Answer based on research & 1 & 0 & 1044 \\
\hline Total & 485 & 559 & 1 \\
\hline
\end{tabular}

a. GRR = Gender Role Relationship 


\section{VITA}

Tamara Gail Coon Sells was born May 28, 1982 in Owosso, Michigan. She attended White Cloud Public Schools in Michigan, where she graduated with honors (2000). She then graduated with honors with a B.S. degree from Central Michigan University (2004), where she majored in Psychology and minored in Family Life and Human Sexuality. She went on to receive a M.S. degree (2007), and a Ph.D. (2012) in Human Development and Family Studies, as well as a Graduate minor in Women's and Gender Studies (2012), from the University of Missouri-Columbia. 